\title{
TECNOLOGÍA LÍTICA DE LAS EDADES DEL COBRE Y BRONCE EN LA MARISMA DEL CUERVO (JEREZ DE LA FRONTERA, CÁDIZ) ${ }^{1}$
}

\section{COPPER AND BRONZE AGE LITHIC TECHNOLOGY IN THE MARISMA DEL CUERVO (JEREZ DE LA FRONTERA, CÁDIZ)}

\author{
por \\ JOSE RAMOS MUÑOZ \\ MARIA VALVERDE LASANTA \\ AGUSTIN ALMAGRO BLAZQUEZ \\ JOSE LUIS ROMERO SANCHEZ
}

\begin{abstract}
RESUMEN Abordamos el estudio de la tecnología lítica prehistórica de la Marisma del Cuervo, reflexionando sobre las actuales perspectivas teóricas de interpretación, considerando las grandes posibilidades que ofrece el Materialismo Histórico. Se presenta el marco de la Marisma y sus potencialidades de recursos líticos. Esbozamos el análisis espacial y diacrónico, para desarrollar los procesos tecnológicos de extracción, talla, desbaste y distribución del utillaje desde los talleres ubicados en los rebordes de Las Peñas de "El Cuervo" hacia la Marisma y otros asentamientos de la Campiña de Jerez.
\end{abstract}

SUMMARY We consider the study of the prehistoric lithic tecnology of the "Marisma del Cuervo" thinking about the present perspectives of interpretation, considering the great possibilities the Historic Materialism offers. The landscape of the "Marisma" and its potentialities of lithic ressources is presented.

We sketch the diachronic and spatial analysis to develope the technological processes of extraction, carving, smoothing and distribution of the tools from the workshops situated on the ledges of the "El Cuervo" cliffs towards the "Marisma" and other settles of the "Campiña de Jerez".

1. El estudio de la tecnología lítica de las Marismas del bajo Guadalquivir se enmarca en un programa de investigación en realización en las Universidades de Sevilla y Cádiz, con la responsabilidad de Enrique Vallespí y José Ramos que aborda el estudio de los talleres e industrias líticas postpaleolíticas del Occidente de Andalucía.

Las prospecciones y el estudio de la Marisma del Cuervo han sido dirigidas por J. Ramos y R. González en el marco del proyecto de investigación en marcha en la Universidad de Cádiz, titulado: "Paleogeografía humana del extremo noroccidental de Cádiz. Los procesos culturales desde el Cobre a época Ibérica", con la dirección de R. González, J. Ramos, D. Ruiz y L. Perdigones.

Han participado en las prospecciones de la Marisma del Cuervo un equipo de alumnos y licenciados en Historia de la Universidad de Cádiz, formado por V. Castañeda, J. Cepillo, J.L. Romero, A. Almagro, I. Córdoba, M.J. Dávila, R. García, I. Lago, L. Lagóstena, A.M. Niveau de Villedury, T. Rodríguez, M.J. Torrejón, M. Valverde, coordinado por J. Ramos y R. González. 


\section{CONSIDERACIONES SOBRE EL MARCO CONCEPTUAL Y ANALITICO EN EL ESTUDIO DE LAS INDUSTRIAS LITICAS TALLADAS}

Hemos asistido en los últimos años al desarrollo de las diversas analíticas que se aplican al estudio de las industrias líticas talladas. Los avances en petrografía, huellas de uso, tecnología experimental, tipologías funcionales, traceología y deposición, se implican en un esfuerzo común por superar las constricciones del paradigma histórico-cultural impuestas a las posibilidades de inferencia de conocimiento sobre las sociedades que generaron el registro arqueológico.

La crítica a la visión normativista de la cultura ha sido explicitada, en general, desde diversos posicionamientos metodológicos (Vicent, 1982; Martínez Navarrete, 1989; Watson, Leblanc, Redman, 1971; Nocete, 1986, 1989; y en particular, ha encontrado en los estudios sobre el paleolítico europeo, donde el análisis de las industrias líticas talladas obviamente acaparaba el centro de atención de la arqueología, la base donde destruir el edificio levantado por la práctica y la teoría normativista (Gamble, 1986). Simplemente los problemas que ahora se plantean las diferentes arqueologías son distintos, como también las técnicas que se aplican en su solución. Las listas tipológicas basadas en las variaciones de estilo de los artefactos líticos han venido a ocupar un lugar más humilde en consonancia con la cantidad de información que pueden aportar a los prehistoriadores.

De la mano del funcionalismo se ha divulgado la mayoría de las nuevas metodologías que inciden en el estudio de los restos materiales. Fundamentalmente se trata del debate normativista-procesual (Ramos Millán, 1982) o, en frase de Gamble (1986), "el paleolítico de Europa puede discutirse en función de dos paradigmas (...) el paradigma de la historia cultural (...) el segundo enfoca la cultura como un sistema adaptativo".

Lógicamente hay otras alternativas. La " arqueología social", el enfoque del materialismo histórico aplicado a la arqueología, del cual nos servimos como marco adecuado para la explicación de los fenómenos socio-económicos que a continuación analizamos.

Las distintas analíticas aplicadas a los estudios de los materiales líticos tallados han incidido en el desarrollo de la cantidad y calidad de la información que sobre los procesos económicos de las sociedades prehistóricas se ha ido acumulando en los últimos tiempos. Sin embargo, y es la tesis que desarrolla Ramos Millán (1982), estos estudios adolecen de falta de integración. Las inferencias de conductas permanecen en el nivel de lo anecdótico o explican inconvenientemente los complejos mecanismos socioculturales al no tener en cuenta los procesos totales en los que los artefactos líticos quedan integrados. Creemos que el concepto de producto generado por el materialismo histórico, explicitado por Ruiz et al, (1986), puede servirnos de forma más conveniente en el intento de establecer marcos teóricos, donde las inferencias de conducta encuentren la adecuada integración.

$\mathrm{El}$ artefacto lítico contextualizado nos permite englobarlo dentro de un proceso de trabajo, donde participa como objeto, medio de trabajo y producto. El artefacto queda así determinado por las condiciones técnicas de producción. Pero dentro de la concepción económica del materialismo histórico que rechaza por igual "la definición formalista de la economía" como "la definición sustantiva" (Godelier, 1973), "el análisis del proceso de producción no puede limitarse al estudio de los factores de producción (...) Todo proceso de producción supone (...) un conjunto de relaciones sociales concretas que determinan el modo de apropiación social" (Ibidem). Esto es, lo que se define dentro del materialismo histórico como relaciones de producción.

Con lo cual queremos dejar sentado que las inferencias que se obtienen a partir de los estudios analíticos van encaminadas a explicitar el desarrollo histórico de determinadas fuerzas productivas y las interconexiones con las relaciones sociales de producción que conforman los dos grandes esquemas 
constitutivos del modo de producción, infraestructura que nos da "el único hilo de engarce que puede servirnos para entender los acontecimientos" (Engels, 1894).

El estudio pormenorizado de este proceso de producción donde queda englobado el artefacto, nos lleva a considerar distintos niveles de análisis de procesos. Los artefactos quedan marcados significativamente y denuncian su participación diferencial en distintos contextos de producción.

En el proceso de suministro de la materia prima lítica se desarrollan estrategias que pueden ir encauzadas a la obtención directa o al suministro, vía intercambio, a través de diferentes patrones de contacto entre formaciones sociales.

En la estrategia de obtención directa podemos encontrar un proceso selectivo-extractivo y/o un proceso selectivo-recolector. Ambos procesos están condicionados por la tecnología desarrollada, por las imposiciones del medio y por la organización social del trabajo. Este proceso se desarrolla en el espacio a varios niveles, que se explican en la mayor o menor complejidad de su organización. De cualquier forma subrayamos la conveniencia de los análisis espaciales regionales, que superan las conductas individuales e integran procesos de superior complejidad. Estos procesos aportan diversos elementos líticos portadores de trazas pertinentes, que son abandonados de forma intencional o accidental.

El transporte de material está condicionado lógicamente por la distancia, la orografía del terreno el desarrollo tecnológico de medios de transporte. El que los productos transportados sean módulos o núcleos, o simplemente soportes o útiles ya elaborados depende en última instancia de estas variables, así como de las características de la materia prima.

A lo largo del proceso de suministro los materiales se van transformando, en el marco de los factores expuestos anteriormente. El material lítico ha podido llegar en diverso grado de transformación. Los núcleos ya descorticados y preparados en forma de elementos soporte o de útiles. Proceso que se relaciona con la tecnología, el trabajo, y la calidad y disponibilidad de la materia. Se orienta a la conversión en producto de la materia prima. Su producción está marcada por la demanda que desde diversas fuentes de consumo se realicen. Se plantean problemas de especialización en el trabajo, de aplicación de técnicas distintas en función de la calidad de la materia prima. Estos productos son distribuidos a través de canales sociales, que afectan al propio asentamiento y/o a otros asentamientos relacionados, dentro de un entramado de roles y jerarquizaciones en distintas escalas.

Los productos son consumidos como medios de producción en actividades en relación directa con la obtención de medios de subsistencia (agrícolas, ganaderos, de caza) y/o como medios de producción en labores artesanales, con actividades domésticas. Por otro lado los productos líticos pueden ser usados directamente dentro de determinados contextos de reproducción ideológica (depósitos funerarios).

No quisiéramos olvidarnos de la movilidad del útil en los procesos de reciclaje y/o reutilización, que le haría pasar de un proceso de consumo a otro de transformación sin solución de continuidad.

La articulación de los procesos en los que participa el artefacto lítico con el territorio no debe abrir una escisión en su comprensión total. El estudio de los instrumentos líticos ha permitido la investigación funcional con base en la ecuación "hombre-tecnología-medio" permitiendo una aproximación ecológica de la cultura (Gándara, 1982,). Pero desde una perspectiva más avanzada ideológicamente, la articulación de toda la información que puede aportar la tecnología lítica junto a otros elementos arqueológicos (asentamientos, fortificaciones, control territorial desde centros nucleares) puede permitir el enmarque en un proceso histórico dialéctico que nos posibilite la superación funcionalista desde parámetros relacionados con el fenómeno "hombre-tecnología-medio-hombre" y así no sólo abordar las relaciones técnicas de producción, sino aspirar al conocimiento de las relaciones sociales de producción. 


\section{MARCO GEOGRAFICO DE LA MARISMA Y PEÑAS DEL CUERVO. EL POBLAMIENTO EN LA PREHISTORIA RECIENTE.}

Las marismas componen un medio de colinas y cerros de muy débiles pendientes, con una amplia serie de canales de mareas (esteros). Han tenido un proceso de colmatación importante en el Holoceno (Díaz del Olmo, 1989), con un paulatino relleno de sedimentos que se hace intenso en época histórica, fundamentalmente en la Edad Media.

Sus suelos son poco productivos debido al elevado componente salino, con lo que en la actualidad sólo son útiles para la explotación de pastos de temporada (García del Barrio, 1988). La bordean suelos de "bujeos" muy aptos para el cultivo cerealístico y de remolachas, así como suelos albarizos asociados al viñedo.

El marco entre Las Peñas del Cuervo y la Marisma es surcado por varios arroyos, Fuente de la Salud, del Pellejero, de la Molineta. Además fluye a la Marisma el importante Arroyo de los Prados, que la pone en contacto con los Llanos de Caulina.

Hidrológicamente se cuenta también con un área endorreica en la Laguna de los Tollos, de conformación pleistocénica, así como numerosos pozos, tanto en los rebordes de las Peñas, como en la ribera de La Marisma.

Entre la Laguna de los Tollos y La Marisma del Cuervo se extiende un ligero declive, una ancha franja de terrenos conformados fundamentalmente por arcillas margosas gris azuladas del Mioceno Superior-Andaluciense, Tortoniense (Martín Ferrero, et al 1977; Zazo, et al, 1988). En esta zona también dominan las margas blancas, limos silíceos con radiolarios y diatomeas. Son las clásicas albarizas del Aquitaniense Medio-Tortoniense Superior (Zazo, et al, 1988). Se corresponden a los clásicos suelos negros, que en la comarca de Jerez se denominan como "albarizas" por su color blanco. Sobre ellas se extienden la mayoría de los viñedos de la zona.

Es una área de compleja y variada naturaleza geológica que se ha considerado en relación con un brazo antiguo del Guadalquivir en el límite Plio-Pleistoceno, a través de los Llanos de Caulina (Zazo, et al, 1985; Chic, et al, 1981; Zazo, 1989).

Junto a ello ha sido muy abordado el problema de la colmatación sedimentaria de la Marisma en el Holoceno (Menanteau y Clemente, 1975; Menanteau y Pou, 1978; Díaz del Olmo, 1989). Se encuentra atravesada por una densa red de canales de drenaje, que la han convertido en tierra apta para la ganadería. Son depósitos grises arcillosos, surcados por antiguos cauces de la red del Guadalquivir (Martín Herrero, et al, 1977) alternados con conglomerados de cantos de areniscas y calizas de matriz arenosa (Zazo,et al, 1988).

Es una zona de cruce de caminos desde la Antiguiedad, dado que en Las Peñas del Cuervo se unen las cañadas, Real de Trebujena, de las Cabezas de San Juan y de Gibalbín. Por todo ello está muy bien comunicada, tanto con el resto de las Marismas, como con la campiña de Jerez.

Desde la Marisma del Cuervo las comunicaciones son muy factibles hacia diversas áreas, Lebrija por las Peñas del Cuervo, Sierra de Gibalbín, por la mencionada Cañada y Llanos de Caulina por el Arroyo de los Prados.

Por tanto se configura esta zona como de grandes posibilidades económicas debido a los suelos de bujeo y albarizas, con abundantes pozos de agua dulce, bien comunicada y con importantes recursos, cinegéticos hacia el piedemonte de la Sierra de Gibalbín y en los rebordes de la Laguna de los Tollos y de la propia Marisma. Igualmente los recursos líticos de rocas silíceas y metamórficas son importantes en los rebordes de las Peñas del Cuervo, con extensiones hacia la Sierra de Gibalbín. En total hemos localizado 34 yacimientos del Calcolítico y Bronce (Ramos, et al, en prensa), (mapa 1). 
Aportamos un avance a la tecnología lítica de la Marisma y Peñas del Cuervo sobre el inventario y clasificación de 17 yacimientos, computando las industrias líticas talladas y pulimentadas. Responden a la siguiente ordenación funcional y diacrónica:

\section{Area de las Peñas del Cuervo}

\section{Asentamientos Atribución cultural}

\begin{tabular}{|l|l|l|l|l|l|l|}
\hline Cortijo del Cuervo Grande 1A & & & C.P. & C.F.-B & B.F.P. & B.F.O. \\
\hline Cortijo del Cuervo Grande 1B & & & & & B.F.P. & \\
\hline Cortijo del Cuervo Grande 2 & & & C.P & & & B.F.O. \\
\hline Cortijo del Cuervo Grande 3 & & & & & & B.F.O. \\
\hline Cortijo del Cuervo Grande 4 & & C. & & & & B.F.O. \\
\hline Cortijo del Cuervo Grande 5 & & & C.P. & C.F.-B & & B.F.O. \\
\hline Peñas del Cuervo 3 & & C. & & & & B.F.O. \\
\hline Peñas del Cuervo 4 & & & & & & B.F.O. \\
\hline
\end{tabular}

Talleres

\begin{tabular}{|c|c|c|c|c|c|c|}
\hline Viña Santa Lucía 2 & N.F. & C. & & & & \\
\hline Peñas del Cuervo 1 & N.F. & C. & C.P. & C.F.-B & B.F.P. & B.F.O. \\
\hline Peñas del Cuervo 2 & N.F. & C. & & & & \\
\hline
\end{tabular}

Talleres con asentamiento

\begin{tabular}{|l|l|l|l|l|l|l|}
\hline Las Arenas & N.F. & C. & & & & \\
\hline
\end{tabular}

\section{Marisma del Cuervo}

Asentamientos.

\begin{tabular}{|l|l|l|l|l|l|l|}
\hline Haza de la Torre 1 & & & C.P. & C.F.-B. & B.F.P & B.F.O. \\
\hline Haza de la Torre 8 & & & & C.F.-B. & & \\
\hline Haza de la Torre 7 & & & & C.F.-B. & & \\
\hline Estación del Cuervo 1A & & & & C.F.-B. & & B.F.O. \\
\hline Haza de la Torre 5 & & C. & & & B.F.P & \\
\hline
\end{tabular}

(N.F. = Neolítico final, $C=$ Calcolítico, C.P. = Calcolítico pleno, C.F. = Calcolítico final-campaniforme, $\mathrm{B}=$ Bronce. B.F.P. = Bronce final precolonial, B.F.O. = Bronce final orientalizante)

Hemos observado una curiosa relación de los tipos de suelos con la distribución de los asentamientos del Cobre y Bronce:

- El núcleo de asentamientos que bordea a Haza de la Torre, junto a la Marisma se sitúa en las mejores tierras de este entorno, en los suelos denominados "bujeos" (García del Barrio, 1988.). Son 
muy arcillosos, que sirven para el cultivo de secano cerealista, remolacha, girasol, maíz, garbanzos, en secano. Corresponden a margas del Eoceno y del Oligoceno. Son las clásicas tierras negras andaluzas (A.A.V.V., 1963).

- Los asentamientos de los rebordes de las Peñas del Cuervo están en contacto con dos tipos de suelos:

- Albarizas. (Asentamientos del piedemonte: Cuervo Chico 3, Cuervo Grande 5, Cuervo Grande 2, Cuervo Grande 1). Corresponden a los clásicos suelos de Xerorrendsinas y Rendsinas de la Campiña de Jerez. Son suelos muy degradados por los intensos cultivos, siendo en la actualidad los característicos suelos de la vid.

- Suelos de terrazas diluvial. (Talleres: Las Arenas y Viña Santa Lucía 2.). Formados sobre sedimentos diluviales arenosos, de color pardo amarillento, pardo rojizo o rojizo y textura arenosa. Contiene gravillas y gravas (importante base de la materia prima lítica).

Quiere decir que las mejores tierras -actuales "bujeos"- estaban en el entorno inmediato de Haza de la Torre, mientras que las Peñas del Cuervo se benefician de los importantes recursos líticos de los guijarros y gravas de los suelos de terraza diluvial, así como de suelos de albarizas aptos para el secano, pero muy degradados..

Creemos que la degradación de las albarizas comienza con factores antrópicos intensivos en la Edad del Cobre, con fenómenos como la tala del bosque natural, el desmonte, las labores y los primeros cultivos sobre el suelo primitivo (A.A.V.V., 1963), produciendo un fenómeno que conducirá a la sobreexplotación en época romana y a la paulatina pérdida de calidad de dicho suelo, que ha condicionado que no sean aptos en la actualidad para el cultivo de secano. (G. del Barrio, 1988)

\section{DISTRIBUCION ESPACIAL E INTERPRETACIONES ECONOMICAS Y SOCIALES}

La Edad del Cobre representa la primera gran ocupación de La Marisma del Cuervo, documentada en la zona con 34 yacimientos de diversas funcionalidades (Mapa 1).

Se ubican fundamentalmente en dos áreas, con clara vocación geográfica y estratégico política, en el reborde occidental de las Peñas del Cuervo y al pie de La Marisma. En ellas se configura un hábitat concentrado de numerosos asentamientos, con vacíos intermedios, pero demostrando una clara organización nuclear como área definida.

En Las Peñas se localizan 7 asentamientos, Cuervo Chico 3, Cuervo Grande 5, Cuervo Grande 2, Cuervo Grande 1A, Cuervo Grande 1C, Peñas del Cuervo 3, Peñas del Cuervo 4, y 7 talleres, Las Arenas, Viña Santa Lucía 2, Laguna de los Tollos 1, Laguna de los Tollos 4, Laguna de los Tollos 10, Montelelle 3 y Peñas del Cuervo 2.

Conforma un hábitat alargado de unos $3,5 \mathrm{Kms}$. en sentido N.O.-S.E. donde los asentamientos adoptan una distribución lineal adaptada a la naturaleza del terreno, (no controlamos aún su dimensión completa por entrar en término de Lebrija), por $1 \mathrm{Km}$. de ancho en sentido E.- O.

Aprovecha una situación geográfica inmejorable con directa relación visual con el otro núcleo situado en el reborde de la Marisma (que se controla perfectamente desde Cuervo Grande 2, Cuervo Grande 1A, Peñas del Cuervo 4 y Peñas del Cuervo 3.), a unos 2,4 Kms. al S.O.. Es un importante enclave de caminos, con numerosos pozos, 10. Las Peñas del Cuervo han sufrido fuertes procesos erosivos y de transformación antrópica.

Esta zona disfruta además de la surgencia de Fuente de la Salud, que actúa como gran abastecimiento permanente de agua y como paso natural, desde la Marisma, hacia las Peñas. 
Los asentamientos mencionados están ubicados en un alineamiento longitudinal adaptado al terreno, en los rebordes y piedemonte de las Peñas del Cuervo. Además de controlar la zona baja de la Marisma, dominan visualmemte la verdadera entrada a la Marisma del Cuervo, en los alrededores de la actual Trebujena, siendo interesante la continuidad geográfica y ocupacional, de esta zona hacia Lebrija.

El área situada junto a la Marisma, constituye también un pequeño territorio nuclear, producto de una organización espacial diferente, ya que un total de 12 asentamientos quedan distribuidos en un aspecto más radial, dominados por el centro nuclear Haza de la Torre 1. Ocupa la cota 25-30 mts. de un cerro de unos $350 \times 350 \mathrm{mts}$. aproximadamente, donde se han observado concentraciones de cabañas bien delimitadas (Haza de la Torre 7 y 8 con material campaniforme). En torno a él se sitúan pequeños asentamientos, como Haza de la Torre 2, Haza de la Torre 5, Haza de la Torre 6, Corchitos 3, Casa de la Torre 1, Casa de la Torre 2, Estación del Cuervo 1, Corchitos 2 y Montegil de Buenavista.

Haza de la Torre 1 domina visualmente el área de las Peñas del Cuervo y de la entrada a la Marisma, en los entornos de Trebujena, sito del importante asentamiento de Cerro de las Vacas, (Alvarez, 1982) dominando incluso toda la zona de la actual Lebrija. (Caro, 1982)

En esta concentración de hábitat se sitúan 6 pozos, estando ubicada por encima de la cota $10 \mathrm{mts}$, que consideramos antigua línea de costa en dicho momento y junto al Arroyo de los Prados, que debía contar con mayor caudal que el actúa. Esta zona también es atravesada por cursos de agua, que drenan hacia la Marisma.

Es un hecho significativo que en estos asentamientos no haya en principio restos de estructuras defensivas de sistemas fortificados, aunque si se aprecian tanto en Haza de la Torre 1, como en Cuervo Grande 1A o Cuervo Grande 2, zonas de concentraciones de cabañas de dimensiones variadas, que rondan los $10 \mathrm{mts}$. de diámetro, con coloraciones más oscuras, pellas de barro cocido y abundantes cerámicas y productos líticos característicos.

La base económica de estas comunidades es esencialmente agrícola, manifiesta por un utillaje variado de abundantes molinos, moletas, así como tecnología básica agrícola con predominio de elementos de hoz. También es muy significativo el importante peso de los utillajes pulimentados, con hachas, azuelas, martillos, cinceles, obtenidos de importantes afloramientos de rocas subvolcánicas (riolita, andesita, diorita) de la sierra de Gibalbín.

Destaca además la importante relación de la concentración de asentamientos en Haza de la Torre con los terrenos de bujeos, muy arcillosos que sirven para importantes cultivos de secano, siendo suelos de gran calidad.

Espacial y funcionalmente estamos ante una muestra de organización en torno a dos claras zonas nucleares. El resto de los asentamientos y localizaciones de Edad del Cobre aparecen de forma más dispersa y puede tratarse de enclaves en función de tierras de labor o del control ganadero (Mapa 1).

Esta clara organización espacial debe ser el reflejo de una estructura social y política, que aún no alcanzamos a atisbar en sus consecuencias, pero que refleja un modelo significativo de control del territorio y de distribución del hábitat, asociado aún a sistemas tribales de organización semisedentaria, donde Haza de la Torre puede ya marcar un importante modelo de asentamiento permanente.

En la reconstrucción paleogeográfica de este entorno cabe destacar el fuerte peso que debió alcanzar el medio de bosque en las Peñas del Cuervo y en los terrenos adyacentes a sus piedemontes, asociado estructuralmente al dominio morfológico de la sierra de Gibalbín. En dicho marco la gran cantidad de objetos pulimentados (Cuadro 5) queda relacionada con un intento de ganar terreno al bosque para la agricultura, donde los actuales terrenos de margas de viñedos y cereales serían feraces tierras, para unos cultivos iniciales de secano significativos. 
La relación macroespacial de estas áreas nucleares será objeto de la continuidad de las prospecciones, donde se deberá relacionar abiertamente con un desarrollo manifiesto de fuerzas productivas, en paralelo a lugares de concentración de excedentes y de distribución de los mismos, como auténticos centros de reproducción de modelo centralizado y jerarquizado. La ubicación central de un hábitat nuclear como Haza de la Torre 1, puede estar en la base de dichos fenómenos socioeconómicos.

A nivel de cultura material se pueden ordenar las diferentes etapas de clasificación tradicional de la Edad del Cobre a partir de parámetros tecnocerámicos, caso de fuentes carenadas para el Neolítico Final-Cobre Antiguo, platos de borde engrosado para el Cobre Pleno y elementos campaniformes para el Cobre Final.

La prueba manifiesta es la continuidad de hábitat al margen de sistemas normativistas de clasificación. En este sentido es muy significativo que los asentamientos importantes caso de Cuervo Grande 1A, Cuervo Grande 5, Cuervo Chico 3 y Haza de la Torre 1 documenten cerámicas campaniformes.

De este modo cabe indicar que la Edad del Cobre se configura como el primer gran poblamiento estable del entorno de la Marisma del Cuervo, con una diversidad funcional de los asentamientos, adaptación y control del territorio a partir de dos áreas nucleares, con clara organización socio-política.

Las escasas investigaciones en la Baja Andalucía en la Edad del Bronce, impiden exponer con claridad la secuencia diacrónica, en la continuidad del Final del Cobre con los inicios y desarrollos del Bronce. Frente a opciones catastrofistas, pensamos que la falta de conocimiento de la cultura material de estos momentos no debe oscurecer la comprensión de la evolución histórica. Además la gran adaptación al territorio, el control del mismo y sobre todo la continuidad manifiesta en los más importantes asentamientos, de elementos materiales del Bronce Avanzado y Final, inciden a considerar la continuidad del Bronce, en parte enmascarado en unos elementos de cultura material parecidos a los del Calcolítico, con la presencia de cerámicas campaniformes, y lisas con cuencos y ollas de bordes entrantes, orzas y grandes vasos para provisiones y entre la tecnología lítica con la continuidad de utensilios productivos como elementos de hoz y la especialización de los artefactos pulimentados.

En dicho marco la constatación de cerámicas características excisas de tipo Cogotas, de nuevo en los asentamientos de Haza de la Torre 1, Cuervo Grande 1A y Cuervo Chico 3, nos mantiene una estrategia poblacional parecida a la de la Edad del Cobre, en torno a las dos áreas importantes, reborde de la Marisma, en la desembocadura del Arroyo de los Prados y Peñas del Cuervo.

La continuidad de las prospecciones y la realización de secuencias estratigráficas en la zona deberá aclarar este problema, que queda enmarcado de una forma amplia en la cuestión de los orígenes y desarrollos de la Edad del Bronce de la Baja Andalucía.

\section{LOS RECURSOS LITICOS}

En los entornos de las Peñas y Marisma del Cuervo hemos diferenciado siete tipos de materias primas que han sido utilizadas del Neolítico al Bronce Final Orientalizante. Presentamos un avance de clasificación morfológica:

Tipo I. Sílex grises, poco densos, desilificados, de mala calidad, de fácil fractura y exfoliación, con colores negro, gris y blanco. En él se han tallado fundamentalmente núcleos levallois y lascas internas, aunque hemos documentado ejemplares levallois y prismáticos. No permite la talla a presión. Procede de Peñas del Cuervo 1, que es una cantera prehistórica utilizada del Neolítico Final al Bronce Final Orientalizante. El sílex aflora en una formación de calizas y margas del Mioceno Superior-Plioceno (Martín,, et al., 1977), en vetas inclinadas de más de dos metros de espesor. Aparece en superficie en 
algunos puntos, donde se documentan áreas microespaciales de talla in situ. De aquí se han transportado núcleos y lascas elaboradas, fundamentalmente sin retocar hacia la Marisma del Cuervo y poblados importantes como El Trobal (Ramos Muñoz, et al., 1989).

Tipo II. Guijarros de sílex rojizo procedentes de los alrededores de Laguna de los Tollos y del piedemonte de Las Peñas del Cuervo. Proceden de los suelos de terraza diluvial (A.A.V.V. , 1963) que contiene gravas y arenas. Se datan en el Mioceno Superior-Plioceno (Martín, et al. , 1977). Además hay que relacionar esta zona con un antiguo brazo del Guadalquivir, que ha depositado numerosos materiales en este medio (Zazo, et al., 1985; Zazo, et al. , 1988). Se documentan entre suelos de arenas del Mioceno Superior-Plioceno (Martín, et al. , 1977). Son más densos y consistentes que los del tipo I, utilizándose así en mayor variedad de artefactos, posibilitando la talla a presión y una mayor diversidad de útiles. Se localiza en los siguientes talleres: Las Arenas, Peñas del Cuervo 2, Viña Santa Lucía 2, Laguna de los Tollos 1,4,10, Montelelle 3, y Peñas del Cuervo 2. Igualmente está muy difundido por toda la Marisma.

Tipo III. Sílex de color blanco, con pátinas beige-amarillentas, de concrecciones calcáreas. Desconocemos su origen y tipos de soportes - guijarros, placas...-, estando bien documentado en La Marisma del Cuervo y en El Trobal.

Tipo IV. Sílex grises y negros de gran calidad, utilizados fundamentalmente para la producción laminar, con aplicaciones directas a útiles bien definidos (laminas con retoque de uso, elementos de hoz, raspadores). Desconocemos su origen pero su calidad nos apunta a una procedencia del Subbético o de talleres del piedemonte de las sierras de Cádiz, como Fuensanta (Ramos Muñoz, et al., 19901991)

Tipo V. Areniscas, utilizadas en lascas del inicio de la talla, internas y lavallois. Aparecen en los suelos de terraza diluvial, debiendo tener un origen similar al tipo II. Se documentan en bloques grandes y medianos en los talleres de las Arenas, Laguna de los Tollos 1, 4, 10. Sobre estos soportes se han realizado los molinos y moletas evidenciados en los asentamientos, así como algunos percutores.

Tipo VI. Cuarcitas. En guijarros de medianos y pequeños tamaños de muy buena calidad. Tienen igualmente un origen fluvial. Abundan en los talleres de Laguna de los Tollos, asociados a la conexión del Guadalquivir con el Guadalete a través de los Llanos de Caulina. Se han elaborado fundamentalmente soportes de útiles, destacando los raspadores.

Además abundan rocas subvolcánicas metamórficas -ofitas- con origen en afloramientos de la Sierra de Gibalbín (Martín, 1977) que explica la importante serie de objetos pulimentados, fundamentalmente en los asentamientos del reborde de las Peñas del Cuervo y en Haza de la Torre.

\section{PANORAMA TECNICO Y TIPOLOGICO}

La primera consideración importante radica en la continuidad técnica de los conjuntos, con un cuadro espacial diferente, destacando un área claramente centrada en el desarrollo de actividades de producción lítica, relacionadas con la transformación de materiales tallados -talleres- en Laguna de los Tollos y Peñas del Cuervo, desde los cuales se distribuyen los productos elaborados hacia los asentamientos de Las Peñas del Cuervo y La Marisma, así como a otras zonas más alejadas situadas en los Llanos de Caulina -El Trobal-.

Históricamente hemos podido controlar el desbaste desde el Neolítico Final, con evidencias en tres talleres (Viña Santa Lucía 2, Peñas del Cuervo 1 y 2) y un taller con asentamiento (Las Arenas). Diacrónicamente hemos comprobado la plenitud de las industrias en la Edad del Cobre y Bronce, 
analizando el sugestivo final de las mismas en momentos plenamente desarrollados del Bronce Final Reciente, con impacto orientalizante fenicio, donde aún siguen utilizándose los objetos tallado con un cierto peso en las actividades domésticas, aunque ya en una evidente decadencia.

La ordenación de las atribuciones culturales que presentamos viene apoyada fundamentalmente en los conjuntos cerámicos que acompañan a las industrias líticas (Ramos, En prensa a), así como por la ordenación de esta. Para ello contamos con el estudio de varios conjuntos bien definidos estratificados que nos son de gran ayuda, en el marco centro-occidental de Cádiz:

- Neolítico Medio-Final: El Estanquillo (San Fernando) (Ramos, En prensa b).

- Transición Neolítico Final-Cobre Antiguo: Cantarranas (El Puerto de Santa María) (Ramos, et al., en prensa, Valverde, en prensa c) ${ }^{2}$, El Trobal (Jerez) (González, 1986; Ramos, et al., 1989)33.

- Cobre Pleno y Final: El Trobal (Jerez). Las Viñas (Rota-El Puerto de Santa María).

- Bronce Pleno: El Estanquillo (San Fernando). (Ramos, J. 1991).

De este modo comenzamos a ordenar diacrónicamente los conjuntos líticos de la Prehistoria Reciente de este importante marco geográfico, aplicando dichos esquemas a la ordenación de los poblamientos y a los comportamientos de los sistemas productivos de las industrias líticas.

De un modo general predominan los restos de talla. En las áreas de taller se evidencia su funcionalidad con el mayor peso de éstos (siempre más del $90 \%$ ). En ellos destaca también la ausencia de objetos pulimentados o de industrias agrícolas (molinos y moletas). Los útiles elaborados alcanzan así una mayor representación en los lugares de hábitats que en los talleres (Cuadro 1).

En los asentamientos hay también evidentes indicios de talla, sobre los soportes elaborados que han llegado de la cantera de peñas del Cuervo 1 y del área de la Laguna ${ }^{4}$. Ello se observa en el importante papel alcanzado por núcleos, lascas y otros (esquirlas, plaquetas, desechos, virutas, flancos de talla, aristas), llegando a constituir el $86,01 \%$ en Haza de la Torre $1,86,41 \%$ en Cortijo del Cuervo Grande 5 o el $90,60 \%$ en Cortijo del Cuervo Grande 2. La importancia cualitativa y cuantitativa de los útiles, la significativa aparición de utillajes pulimentados y de actividades agrícolas con molinos, moletas, junto a los conjuntos cerámicos y las características topográficas de los mismos, avalan la consideración funcional (Cuadros 1 y 5).

El proceso de desbaste y talla de los recursos disponibles varía lógicamente en el desarrollo del proceso histórico. De cualquier modo, asistimos aquí dada la importancia alcanzada por la materia prima de Peñas del Cuervo 1 (sílex del tipo I) y los sílex rojizos (tipo II) a una evolución tecnológica muy uniforme que conlleva un "continuum tecnológico dinámico", al menos comprobado desde el Neolítico Final al Bronce Pleno, con claros indicios de retraimiento de técnicas en el Bronce Final.

Los modelos de desbaste y talla permiten hablar de auténticas "cadenas operativas", donde los objetos son sometidos a proceso artesanales uniformes y estandarizados. Los sílex del tipo I se prestan a un desbaste para núcleos globulosos, que representa el tipo mejor documentado (Cuadro 2), tanto en los talleres (de 35 a $50 \%$ ), como en los asentamientos (superando el $70 \%$ de los núcleos). Manifiestan una talla de desbastes sucesivos de carácter rotativo. Dada la fragilidad del sílex tipo I, los ejemplares

2. El yacimiento de Cantarranas es el tema de la Memoria de Licenciatura (Valverde, en prensa) de M. Valverde. Agradecemos a F. Giles todas las facilidades prestadas para el estudio de este conjunto depositado en el Museo del Puerto de Santa María (Valverde, e.p.).

3. Agradecemos a R. González la gentileza de la cesión temporal del material del yacimiento "El Trobal", depositado en el Museo de Jerez de la Frontera. Por su parte, L. Perdigones nos ha permitido el estudio del material lítico de las Viñas, procedentes de las excavaciones de urgencia por él dirigidas.

4. En este sentido, A. Almagro realiza su Memoria de Licenciatura sobre la tecnología lítica prehistórica de la Marisma del Cuervo. 
tallados con él, son generalmente de aspecto informe y tendencia poliédrica, para lascas y láminas internas.

En el Neolítico Final predominan los núcleos prismáticos y para hojas, característicos de un desbaste de microlaminillas estrechas de talla a presión (Viña Santa Lucía 2. Cuadro 2), y los levallois.

En la Edad del Cobre vemos el predominio de los globulosos-poliédricos, junto a levallois, con un mantenimiento de prismáticos y constatación de núcleos con otras técnicas, como ejemplares sobre lascas con un plano de golpeo.

En el Bronce Final y con el predominio significativo del sílex de tipo I, asistimos a una práctica reducción a núcleos globulosos y diversos, que están muy agotados. En general son las últimas fases del desbaste de núcleos poliédricos.

De una forma general los tipos de núcleos de la Marisma del Cuervo tienen planos de golpeo preparados lisos, que conllevan el desbaste de lascas con talones lisos, siendo casi inexistentes las de talones facetados. Talones corticales están documentados en sílex del tipo II, a partir de un desbaste de guijarros en los planos naturales.

Tipométricamente los productos desbastados son prioritariamente de pequeño tamaño en el Neolítico Final, con hojas estrechas de 5-9 mms. Hay una ligera tendencia a elaborar lascas de mayores dimensiones en la Edad del Cobre, destacando en ello los sílex de tipo IV, con grandes lascas y láminas de gran calidad. En el Bronce Final vemos de nuevo una reducción considerable de lascas y una casi inexistencia de hojas.

Los productos de talla -lascas- confirman la idea de "cadena operativa", desde las del inicio de la talla, a internas y levallois (Cuadro 3). Las lascas del inicio de la talla (de descortezado y de semidescortezado) son más frecuentes en los talleres, oscilando del 12 al $22 \%$.

En todas las etapas consideradas predominan las lascas internas, tanto en los talleres, como en los asentamientos; representando más del $65 \%$ en 11 de las localizaciones consideradas.

Lascas y láminas levallois tienen una mayor frecuencia en los asentamientos (Cortijo del Cuervo Grande 1A, 27,12\%, o Haza de la Torre 1, 15,79\%).

Las hojas de talla a presión son muy definidas en el Neolítico Final, sobre todo en Viña Santa Lucía $2(15,16 \%)$ y Peñas del Cuervo $2(15,19 \%)$; observando un descenso generalizado en la Edad del Cobre. Ello se relaciona con la casi imposibilidad de su producción sobre los soportes de los sílex de tipo I y II. No hemos observado su presencia en contextos de Bronce Final.

Como fenómeno tecnológico asociado es indicativa la documentación de láminas de cresta y de lascas del desbaste de núcleos para hojas (Cuadro 3).

Entre los restos de talla también son muy significativos, los elementos obtenidos en el proceso de la talla, como esquirlas, virutas, flancos, aristas, plaquetas, desechos (agrupados bajo el concepto "Otros" en el Cuadro 1). Alcanzan una gran representatividad en los talleres, oscilando de 27 a $39 \%$ y tienen también una significativa presencia en los asentamientos (Cuadro 1).

Los productos elaborados y transformados por retoques nos ayudan a la definición del modelo diacrónico. A pesar de ello resulta complicada la adscripción directa de los utillajes, considerando que en la mayoría de los yacimientos localizados vemos una presencia amplia, con varias ocupaciones. En este sentido sólo tienen una fase de hábitat, Cortijo de Cuervo Grande 1B, en Bronce Final Precolonial; Cortijo del Cuervo Grande 3 y Peñas del Cuervo 4, en Bronce Final Orientalizante; y Haza de la Torre 7 y 8 en Cobre Final.

El Neolítico Final documentado en Viña Santa Lucía 2, Peñas del Cuervo 1 y 2 y Las Arenas, se evidencia sólo en áreas de taller. Se utiliza sobre todo sílex de los tipos I y II. También observamos del tipo IV para los productos más seleccionados -raspadores, perforadores-. Se caracteriza por un signifi- 
cativo mantenimiento de los útiles del sustrato paleolítico: raspadores, perforadores-taladros, buriles. Se evidencia aún elementos del sustrato epipaleolítico (Ramos, 1988-89 c -Zephyrus), con láminas con borde abatido y retoques continuos y de uso (Cuadro 4).

Además asistimos a la aparición de los elementos de hoz, como se confirma en asentamientos estratificados como El Trobal (Jerez), La Viña (Rota-El Puerto de Santa María).

Para la Edad del Cobre no podemos aún estructurar una evolución diacrónica totalmente coherente. Están en marcha los estudios estratigráficos mencionados y esperamos poder presentar esquemas más elaborados en breve tiempo (4). La Marisma del Cuervo se mantiene en una tónica general común a la Andalucía Centro-Occidental (Vallespí, et al., 1988). Tienen buena presencia los raspadores y cepillos, se evidencian buriles y perforadores-taladros así como muescas y denticulados. Otro buen grupo lo constituyen lascas y láminas con retoques continuos (generalmente abruptos) y de uso, destacando la plenitud de los elementos de hoz (Cuadro 4).

El Cobre Final-Bronce queda muy bien definido por las cabañas de Haza de la Torre 7 y 8, con localizaciones microespaciales en Haza de la Torre 1, con cerámicas campaniformes en ocupación monofásica, en un radio de acción no superior a 30 x $30 \mathrm{mts}$. Destaca por la presencia de raspadores, muescas y denticulados, hojitas con retoque de uso y elementos de hoz (Cuadro 4), acompañados en menor presencia por retoques abruptos y foliáceos.

La continuidad cronológica del Bronce, desde el fenómeno campaniforme va a venir manifestada por los elementos de hoz.

El Bronce Final no constituye "per se" una degeneración tipológica. Hemos señalado la reducción de los tipos a un nivel dimensional, observando el mantenimiento de utillajes básicos de sustrato, al menos en el Bronce Final Precolonial, destacando una cierta perduración de utillajes domésticos y productivos en el Bronce Final Orientalizante. Este fenómeno ha quedado bien contrastado en una cabaña del Trobal (Jerez) (Ramos, 1991; González, Ramos, En prensa). Observamos de este modo la perduración de raspadores, cepillos, muescas, retoques abruptos y de uso, destacando los útiles vinculados con la siega, como elementos de hoz, o truncaduras (Ramos, En prensa d). Esta significativa perduración se viene también comprobando en los poblados de Jerez, como Casa Blanquilla y La Mariscala (Ramos, et al., 1989).

El fenómeno de la paulatina desaparición de la tecnología lítica con la introducción del hierro y los contrastes costa-interior en una zona como ésta, fuertemente influenciada por los aportes orientalizantes en la Protohistoria, vienen a poner de actualidad los ya clásicos planteamientos de E. Vallespí sobre el problema de la perduración y extinción de las industrias líticas en la Prehistoria peninsular (Vallespi, 1959, 1961).

La continuidad estratigráfica, tecnológica y tipológica se confirma en los asentamientos de hábitats prolongado, como Haza de la Torre 1 y Cortijo del Cuervo Grande $1 \mathrm{~A}$.

Las industrias líticas no talladas van a ayudar a completar el panorama funcional. Aparecen en el Neolítico Final-Inicios del Cobre en Las Arenas, en la zona de hábitat de este yacimiento. Aquí se constatan hachas, martillos y fragmentos pulimentados partidos, así como un molino de mano (Cuadro 5).

En el Cobre vemos la máxima aparición de la tecnología de los objetos pulimentados, con hachas, martillos, fragmentos partidos de cinceles y escoplos; así como una gran evidencia de molinos y manos de molino, en los asentamientos de Peñas del Cuervo y en Haza de la Torre.

En el Cobre Final-Bronce veremos el mantenimiento de los objetos pulimentados y de los molinos y moletas.

En el Bronce Final de la Marisma del Cuervo apreciamos la casi total desaparición de elementos pulimentados y la significativa perduración de los molinos (Cuadro 5). 


\section{SINTESIS, PRODUCCION Y DISTRIBUCION DE LOS RECURSOS LITICOS EN LAS PEÑAS DEL CUERVO}

Como ha podido comprobarse en este trabajo, estamos aún lejos de la consideración analítica total propuesta. Aún siendo un avance al estudio de la tecnología de las Peñas y Marismas del Cuervo, contamos con limitaciones. La industria procede de recogida superficiales en prospecciones sistemáticas. Ello no posibilita la información microespacial en los asentamientos e incide en un cuadro diacrónico que todavía no esta sujeto a un completo desglose.

A pesar de ello, el enmarque de los asentamientos y talleres en la distribución espacial de los asentamientos del Cobre y Bronce permite concluir con una exposición del modelo de producción y distribución de los recursos líticos en el área de las Peñas del Cuervo:

1. El área de extracción más importante se encuentra en Peñas del Cuervo 1, que conforma una cantera de aprovechamiento masivo del material -sílex tipo I-. Esta fuente de recursos es aprovechada desde el Neolítico Final al Bronce Final Orientalizante.

2. Los talleres (Viña de Santa Lucía 2, Peñas del Cuervo 1 y 2, Las Arenas, Laguna de los Tollos 4 y 10 , Montelelle 3) son lugares de transformación, talla y desbaste de núcleos en forma de guijarros tipo II, V y VI.

Se encuentran en los rebordes de la Laguna de los Tollos, en suelos de terraza diluvial ricos en gravas, con numerosos guijarros brutos y abundante materia prima. Se trata de lugares de producción para la transformación del material en soportes de núcleos y. lascas, con elaboraciones directas de útiles en variadas tipologías. Estos talleres cubren cronológicamente del Neolítico Final al Cobre, con constatación de que incluso en el Bronce Final se utiliza material del tipo II, característico de los rebordes de la Laguna de los Tollos.

3. Dicho fenómeno de 7 talleres líticos en un área tan reducida debió constituir una causa importante del rico enclave de asentamientos en las propias Peñas del Cuervo y en su piedemonte inmediato.

4. La producción, control y distribución de dichas materias primas debió estar a cargo de los asentamientos situados en dicho enclave (Mapa 1), siendo Cuervo Grande 1A, el que cubre toda la secuencia cronológica documentada.

5. Existe una variada utilización de técnicas, comunes en la Prehistoria Reciente de Andalucía Occidental, levallois, talla poliédrica, desbaste de hojas, para la elaboración de utensilios vinculados tanto con actividades relacionadas con la producción directa de labores agrícolas (elementos de hoz, truncaduras, retoques de uso), como con trabajos domésticos (raspadores, buriles, perforadores).

6. Se ha podido rastrear un sucinto balance del cuadro diacrónico, desde el Neolítico Final al Bronce Final, siendo muy sugerente la problemática de la gran perduración de las tecnologías en momentos ya plenamente orientalizantes.

7. Junto a las industrias talladas, los elementos pulimentados procedentes de Gibalbín, fundamentalmente en ofitas, completan el panorama económico, con gran variedad de utensilios relacionados con la desforestación y la agricultura. En este sentido, se debe iniciar en la Edad del Cobre el proceso de utilización intensiva de los tipos de suelos de albariza, situados en las inmediaciones de las Peñas del Cuervo., que en dicho momento debieron ser muy aptos para el cultivo de cereales, tal y como lo demuestran la significativa presencia de elementos de hoz en los asentamientos de dicha área, así como molinos y moletas.

8. El área adyacente a la Marisma no cuenta con materias primas originales en su espacio de localización, quedando su procedencia abastecida fundamentalmente de los talleres indicados en Peñas del Cuervo. Además es muy significativa la presencia de buenos sílex -tipo IV- de posible origen en el Subbético -más de 50 kms-. 
9. Tecnológicamente cuenta esta zona con cuadros técnicos y tipológicos similares a las Peñas del Cuervo, con clara diferenciación funcional y de control espacial y político a partir de Haza de la Torre.

Los fenómenos de distribución del sílex a tal nivel de intensidad, de aprovechamiento de una auténtica cantera-mina y de proyección amplia, constatada en el poblado de El Trobal a más de 15 kms., coloca el fenómeno del "intercambio" en un lugar importante. Dichas actividades, unidas a la gran concentración de objetos relacionados con la agricultura de cereal en Haza de la Torre, sus dimensiones y el claro sentido central que ejerce sobre el resto de los asentamientos de la Marisma inciden en la consideración de dicho asentamiento como centro de distribución de exedentes agrícolas de la producción, que debe estar a su vez vinculado con algún centro de mayor envergadura, que desconocemos todavía, pero que puede estar en relación con poblados como Cerro de las Vacas (Alvarez, 1982), Lebrija (Caro, 1982) y El Trobal (González Rodríguez, 1986).

El hábitat permanente desde los inicios del Cobre hasta momentos finales del Bronce en Haza de la Torre 1 y Cortijo del Cuervo Grande 1A permite considerar la superación del hábitat semisedentario, dado que estamos ante poblados permanentes que aprovechan durante siglos los importantes recursos líticos y están directamente vinculados con actividades agrarias del cereal de secano.

Todo este esquema técnico y productivo, debe estar en relación con una organización social importante, que es capaz de articular dicho proceso, de relaciones técnicas y sociales de producción, en el marco de aparatos políticos consolidados, que controlan la distribución, tanto de la tecnología lítica, como de la producción cerealista.

La continuidad de la prospección en el resto de las Marismas del Guadalquivir, y en las grandes áreas de contacto con las campiñas y buenas tierras del interior -Lanos de Caulina- serán decisivas para seguir profundizando en los modelos de explotación tecnológica y en la sociedad que es capaz de ponerla en marcha. 


\section{BIBLIOGRAFIA}

ALVAREZ, A. 1982: "Idolo cilíndrico del Cerro de las Vacas. Trebujena (Cádiz)". Zephyrus XXXIV-XXXV: $119-121$.

A.A.V.V., 1963: Estudio agrobiológico de la provincia de Cádiz. Excma. Diputación Provincial de Cádiz. Cádiz.

CARO, A. 1982: "Notas sobre el Calcolítico y el Bronce en el borde de las marismas de la margen izquierda del Guadalquivir". Gades 9: 71-90.

CHIC, G., DIAZ DEL OLMO, F. y CABALLOS, A., 1981: "Un posible enlace entre las Marismas del Guadalquivir durante la antigüedad clásica". V Reunión del Grupo Español de Trabajo del Cuaternario : 199-200. Sevilla.

DIAZ DEL OLMO, F., 1989: "Paleogeografía Tartésica". En AUBET, M.E. : Tartessos. Arqueología protohistórica del Bajo Guadalquivir, pp. 13-23. Barcelona.

ENGELS, F., 1975: Obras escogidas de Marx y Engels. Tomo II. Editorial Fundamentos. Madrid.

GAMBLE, C., 1986: The Palaeolithic settlement of Europe. Cambridge University Press. Cambridge.

GANDARA, M., 1982: "La vieja "Nueva Arqueología". En Teorías, Métodos y Técnicas en Arqueología : 59159. Méjico.

GARCIA DEL BARRIO, I., 1988: "Mapa de suelos de la provincia de Cádiz. Jerez de la Frontera". No 1. E. I: 50.000. Junta de Andalucía. Consejería de Agricultura y Pesca. Dirección General de Investigación y Extensión Agrarias. Sevilla.

GODELIER, M., 1980: "Economic institutions" in People in Culture. A Survey of Cultural Anthropology: J.F. Bergin Publishers, Inc. New York.

GONZALEZ RODRIGUEZ, R., 1986: "El yacimiento de "El Trobal" (Jerez de la Frontera, Cádiz). Anuario Arqueológico de Andalucia 1986. III Actividades de Urgencia : 82-88. Sevilla.

GONZALEZ RODRIGUEZ, R. y RAMOS MUÑOZ, J., (en prensa): "Análisis funcional y material de una cabaña del Bronce Final en el poblado del Trobal (Jerez de la Frontera)".

MARTIN HERRERO, D. et al., 1977: "Lebrija". Mapa Geológico de España. E. 1: 50.000. Hoja 1.034, 12-43. IGME. Madrid.

MARTINEZ NAVARRETE, M. I., 1989: Una revisión crítica de la Prehistoria española : la Edad del Bronce como paradigma. S. XXI Madrid.

MENANTEAU, L. y CLEMENTE, L., 1975: "Variaciones de la influencia marina y su incidencia en la transformación del paisaje aluvial del delta del Guadalquivir durante los dos últimos milenios". Actas de la II Reunión Nacional del Grupo de Trabajos del Cuaternario : 167-176. Jaca.

MENANTEAU, L. y POU, A., 1978: "Las marismas del Guadalquivir: apport de la télédétection et de l'Archéologie à la reconstitution du Paysage". Caesarodunum. Colloque "Pour une archeólogie du Paysage": 174-192. París.

NOCETE, F., 1986: “Una historia agraria: el proceso de consolidación de la economía de producción (perspectivas en la investigación de las edades del Cobre y Bronce en el Alto Guadalquivir)". En RUIZ, A., MOLINOS, M. y HORNOS, F. : Arqueología en Jaén (reflexiones desde un proyecto arqueológico no inocente) : 91-99. Jaén.

NOCETE, F., 1989: El espacio de la coerción. La transición al estado en las campiñas del Alto Guadalquivir (España) 3000-1500 a.C. B.A.R. International Series 492. Oxford.

RAMOS MILLAN, A., 1982: "Hacia un enfoque sintético en los estudios de los artefactos líticos tallados". Cuadernos de Prehistoria de la Universidad de Granada 7,: 405-422.

RAMOS MUÑOZ, J., SANTIAGO, A., MOLINA, M.I., MATA, E. y GONZALEZ, R., AGUILERA, L. y GUTIERREZ, J.M., 1989: Arqueología en Jerez. Primera aproximación al estudio de las industrias líticas de su Prehistoria reciente. B.U.C. Jerez de la Frontera.

RAMOS MUÑOZ, J., SANTIAGO, A., MOLINA, M.I., MATA, E. y GUTIERREZ, J.M., 1990-1991: "Fuensata (Arcos de la Frontera). Un gran taller del Calcolítico y Bronce en la presierra del Noroeste de Cádiz".Butlletí de l'Associació Arqueológica de Castelló "Llansd de Romaní": 9-11: 68-84. Castellón. 
RAMOS MUÑOZ, J. GILES, F., GUTIERREZ, J.M., SANTIAGO, A., BLANES, C., MATA, E. y MOLINA, M.I. en prensa: "Aproximación tecnológica a la transición Neolítico-Calcolítico. El taller de Cantarranas (El Puerto de Santa María)". Primer Coloquio de Historias Locales. 1989. Cádiz.

RAMOS MUÑOZ, J. y GONZALEZ RODRIGUEZ, R. en prensa: "Prospección arqueológica superficial en el término municipal de Jerez de la Frontera, Cádiz. Campaña 1990". Anuario Arqueológico de Andalucía. Actividades Sistemáticas. 1990. Sevilla.

RAMOS MUÑOZ, J. 1991: "El Estanquillo. Análisis microespacial de un asentamiento de la Edạd del Bronce". Revista de Arqueología 122: 14-23. Madrid.

RAMOS MUÑOZ, J. 1991b: "Las industrias líticas del Bronce Final en Jerez. Renovación metodológica y perspectivas económicas de estudio". Páginas Revista de Humanidades 10: 28-39. Jerez de la Frontera.

RAMOS MUÑOZ, J. en prensa a: "Talleres líticos de la prehistoria Reciente de Cádiz". Il Congreso Internacional "El Estrecho de Gibraltar". Ceuta. Noviembre 1990.

RAMOS MUÑOZ, J. en prensa b: "Informe de excavación de urgencia realizada en el asentamiento prehistórico de "El Estanquillo" (San Fernando, Cádiz)". Anuario Arqueológico de Andalucía. Actividades de Urgencia. 1990. Sevilla.

RAMOS MUÑOZ, J. 1988-89: "Las industrias líticas del Neolítico en Andalucía, sus implicaciones espaciales y económicas". Zephyrus. XLI-XLII: 113-148. Salamanca.

RAMOS MUÑOZ, J. 1991-92: "Ensayo de clasificación analítica de los elementos de hoz". Anales de la Universidad de Cádiz. VII-VII: 557-572. Cádiz

RUIZ, A. , MOLINOS, M., NOCETE, F. y CASTRO, M., 1986: "Concepto de producto en Arqueología". Arqueología espacial 7. Coloquio sobre el microespacio 1. pp.63-80. Teruel.

VALVERDE LASANTA, M. en prensa: El taller de Cantamanas (El Pto. de St ${ }^{a}$ María, Cádiz). Un ejemplo para la transición neolítico/calcolítico. Servicio de Publicaciones. Universidad de Madrid.

VALLESPI, E. , 1959: "Bases arqueológicas para el estudio de los talleres de sílex del Bajo Aragón. Hacia una seriación de las industrias líticas postpaleolíticas bajoaragonesas". Caesaraugusta-Psana 13-14: 7-20. Zaragoza.

VALLESPI, E. , 1961: "Sintesis del estado actual del conocimiento de las industrias macrolíticas postpaleolíticas del cuadrante nordeste de España". VI C.N.A. Oviedo 1959: 64-72. Zaragoza.

VALLESPI, E. , RAMOS MUÑOZ, J. , MARTIN CORDOBA, E. , ESPEJO, M. Y CANTALEJO, P. , 1988: "Talleres líticos andaluces del Calcolítico y Bronce". Revista de Arqueología 90: 14-24.

VICENT, J.M., 1982: “Las tendencias metodológicas en Prehistoria”. Trabajos de Prehistoria 39: 9-53.

WATSON, P.J. , LEBLANC, S.A. y REDMAN, CH.L., 1971: Explanation in archeology. An explicitly Scientific approach. Columbia University Press.

ZAZO, C., GOY, J.L. DABRIO, C.J., CIVIS, J. y BAENA, J., 1985: "Paleografía de la desembocadura del Guadalquivir al comienzo del Cuaternario (provincia de Cádiz, España)". I Reunión del Cuaternario Ibérico: 461-488. Lisboa.

ZAZO, C. et al., 1988: "Jerez de la Frontera". Mapa Geológico de España. E. 1: 50.000. Hoja 1048, 12-44. IGME. Madrid.

ZAZO, C, 1989: "Los depósitos marinos cuaternarios en el Golfo de Cádiz". El Cuaternario en Andalucía Occidental. AEQUA Monografías, $1: 113-122$. Sevilla. 

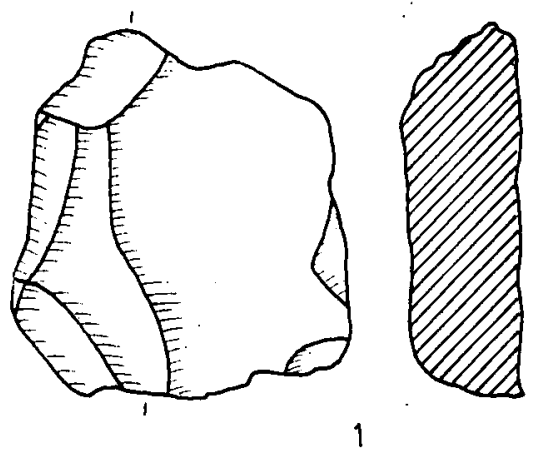

1
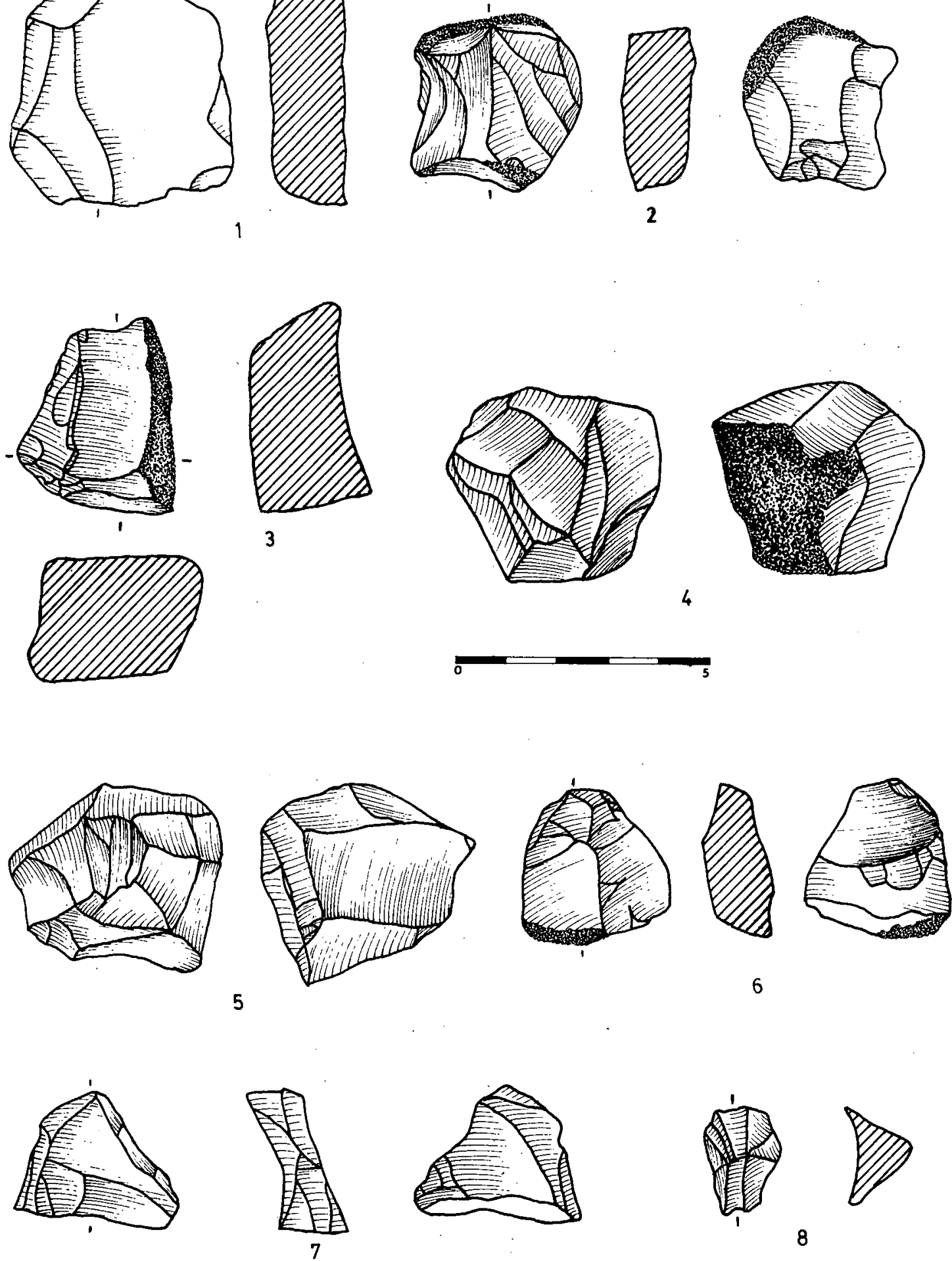

Figura 1.

Las Arenas. Núcleos: levallois (1,2), prismático (3), globulosos $(4,5)$, sobre lasca (6) y para hojas $(7,8)$. 

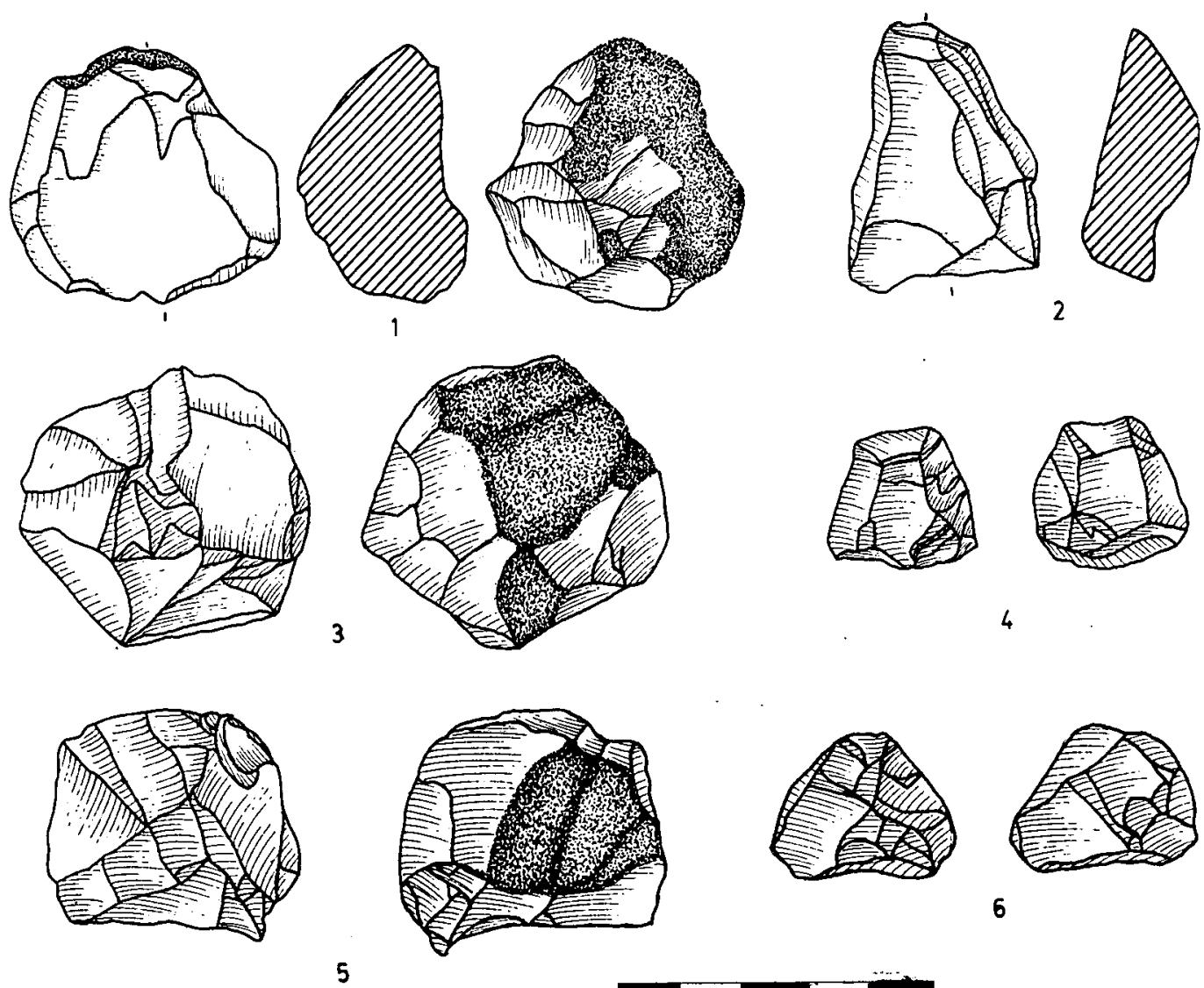

6

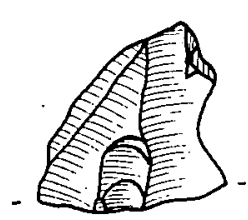

7
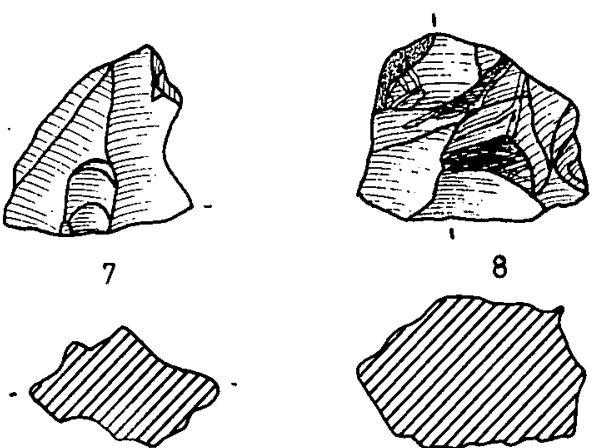

8
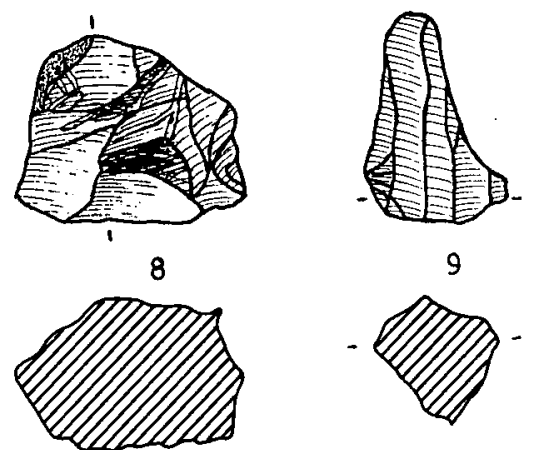

9
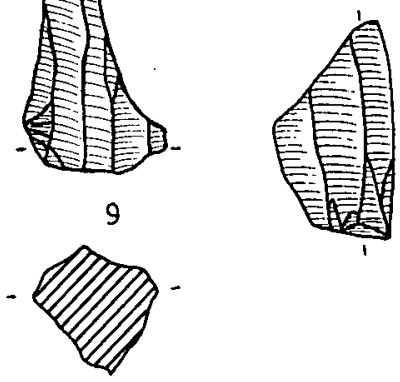

10
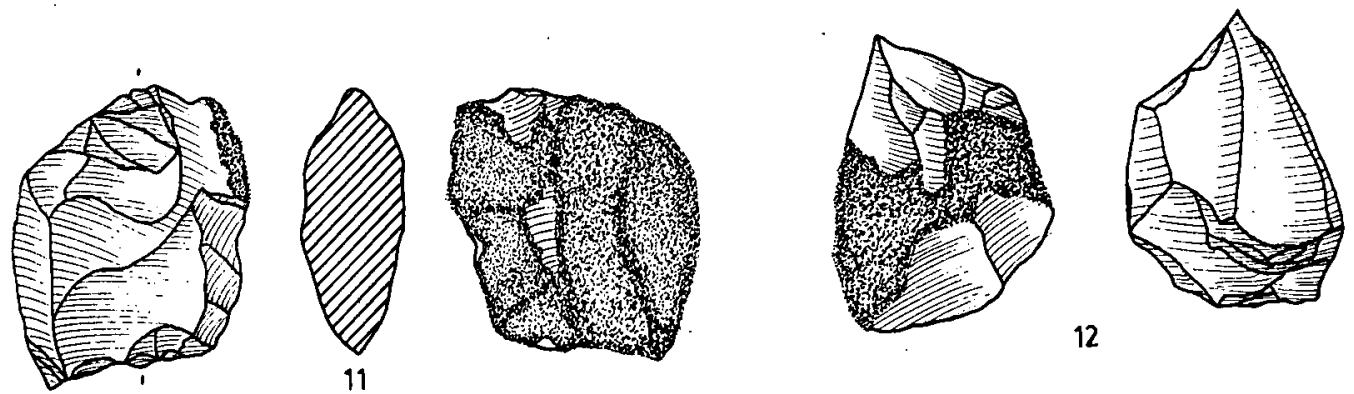

Figura 2.

Viña Santa Lucía 2. Núcleos: levallois (1,2), globulosos (3 a 6), prismáticos (7 a 9), para hojas (10,12), y sobre lasca (11). 

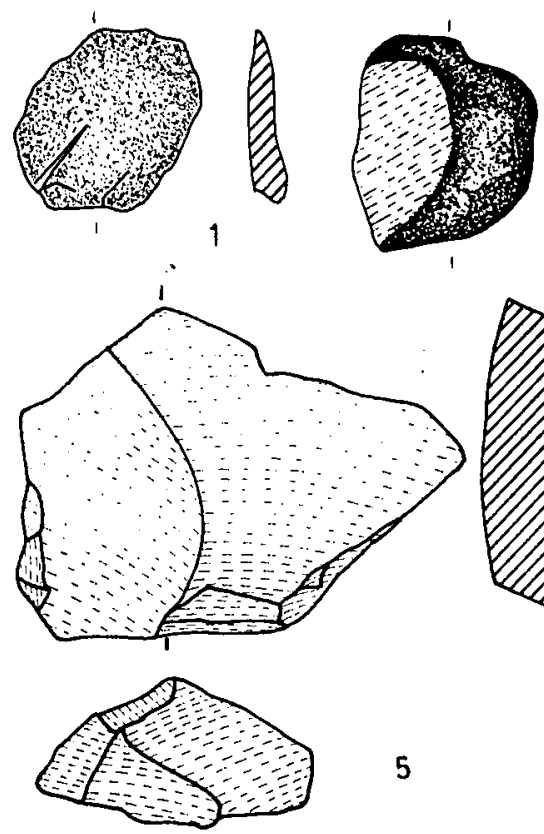

5
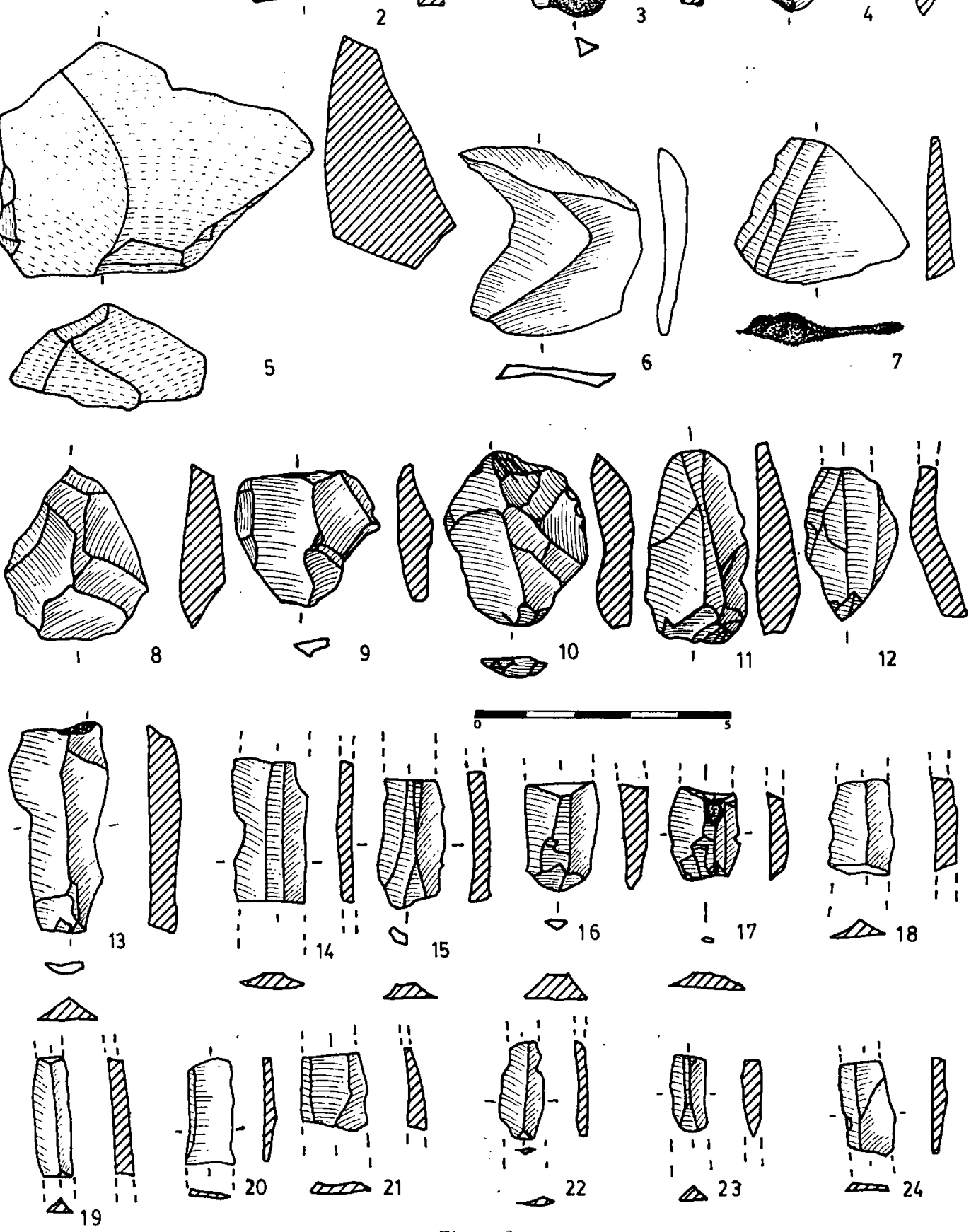

Figura 3 .

Viña Santa Lucía 2. Lascas: de descortezado (1), de semidescortezado (2 a 4), internas (5 a 7), levallois (8 a 12), $y$ hojas (13 a 24). 

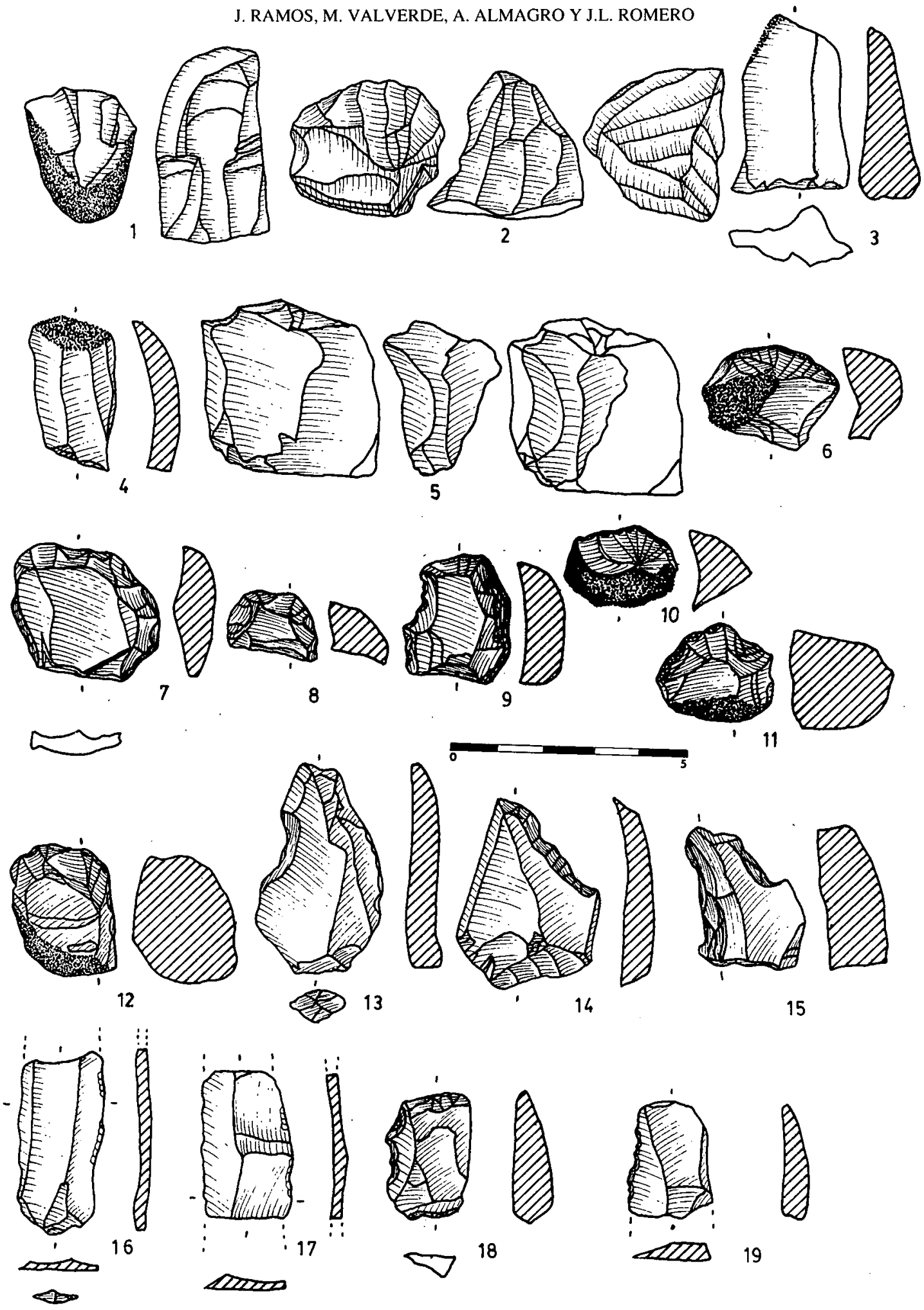

Figura 4.

Cortijo del Cuervo Grande 1A. Núcleos prismáticos (1,2) Lascas: levallois $(3$ a 5, $5=$ remontaje de dos lascas levallois). Utiles: raspadores $(6$ a 9,12$)$, cepillos $(10,11)$, muesca (13), denticulado (14), retoques abruptos (15), retoques de uso (16,17), y elementos de hoz $(18,19)$. 

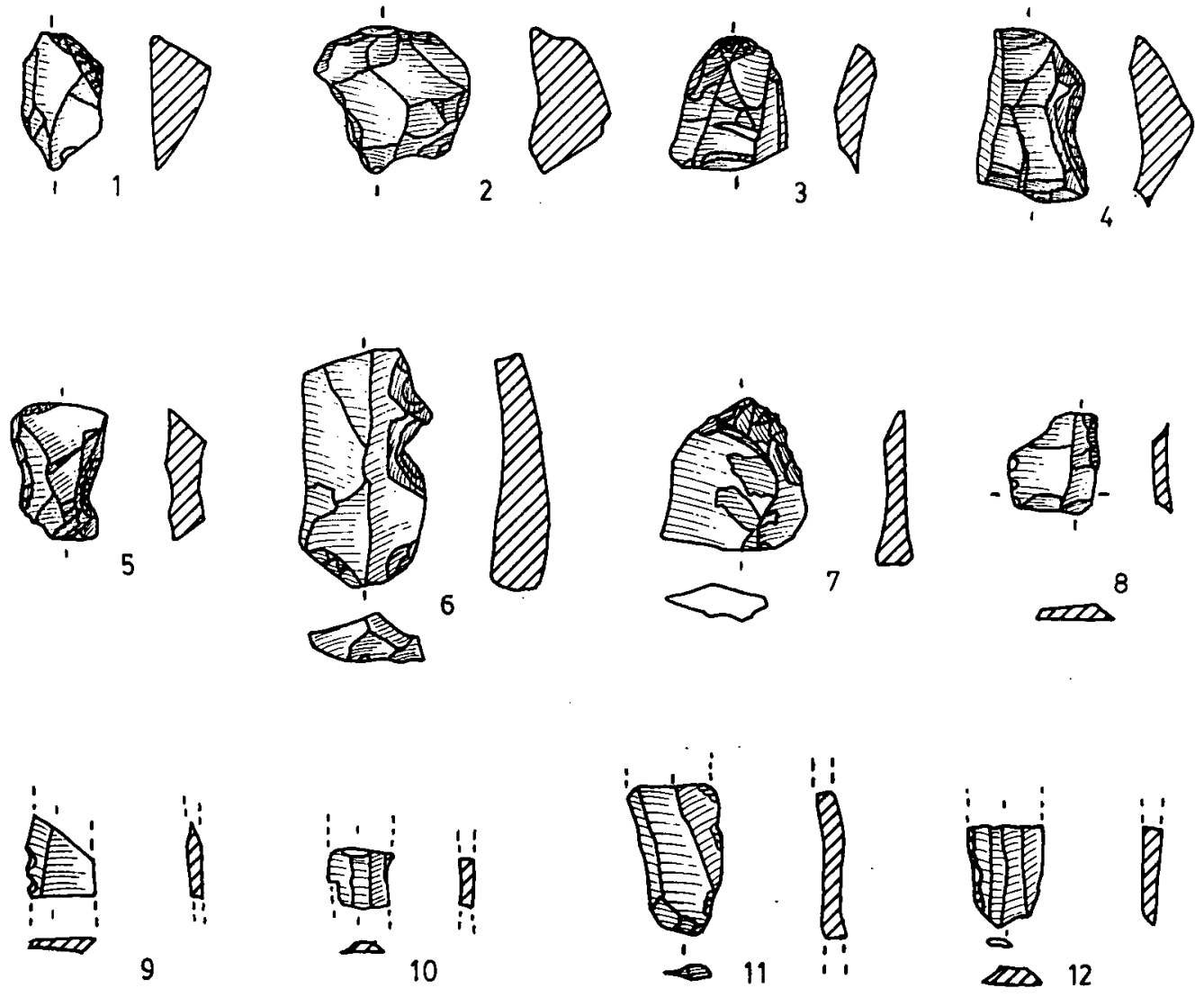

$\infty$
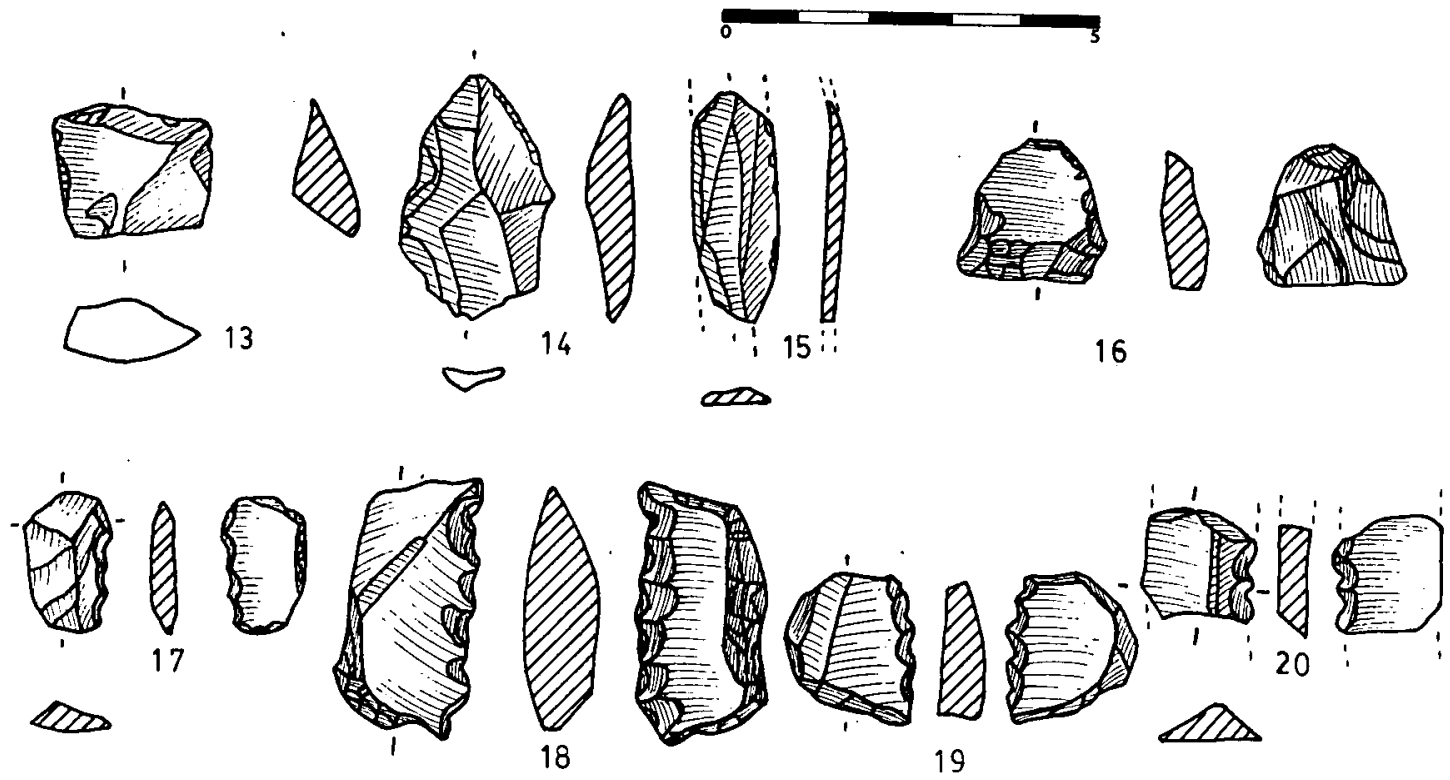

Figura 5.

Haza de la Torre 8. Utiles: raspadores (1 a 3), muescas (4,5), denticulados (6,7), retoques de uso (8 a 15), retoques planos (16), y elementos de hoz (17 a 20). 


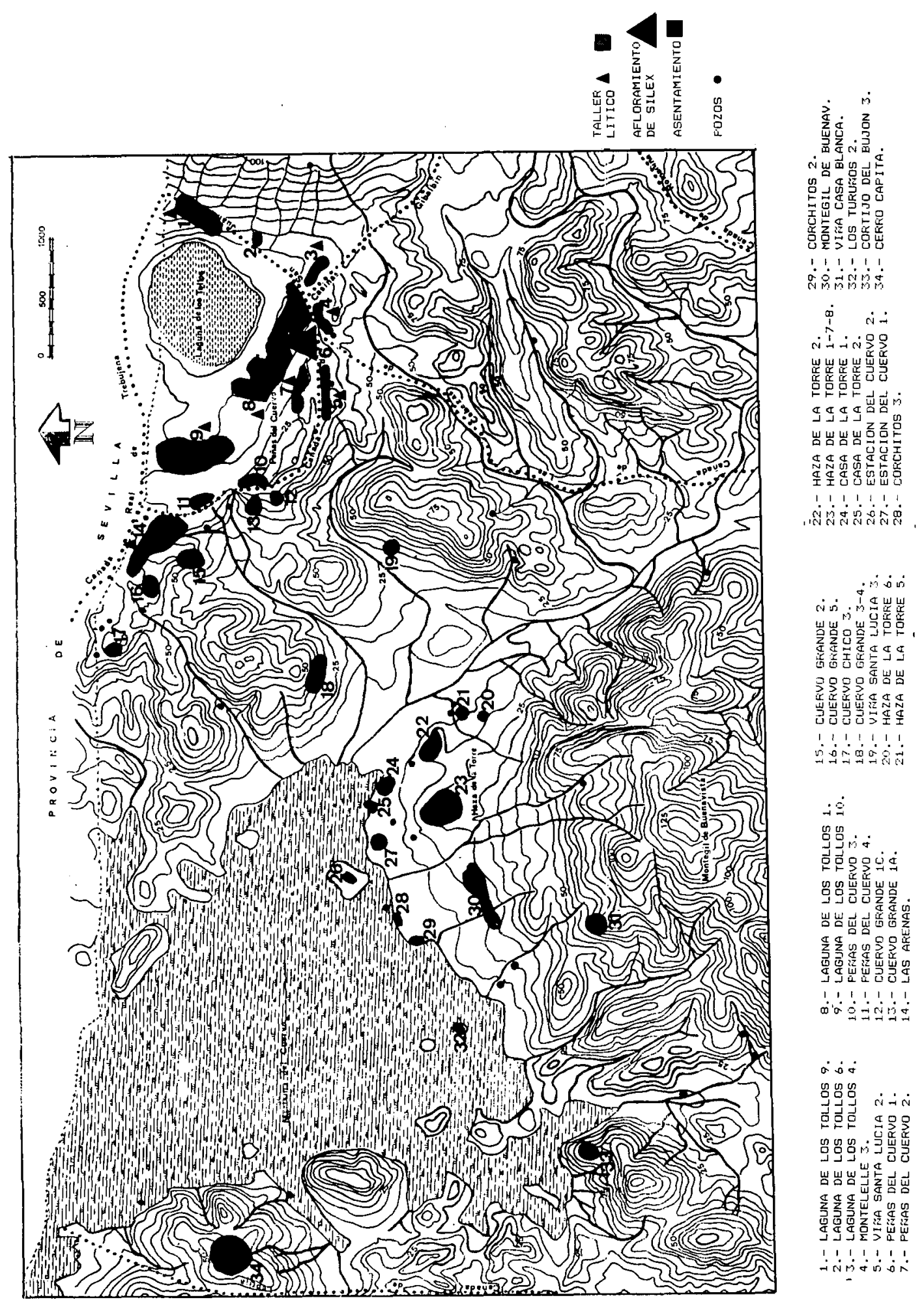




\section{CUADRO 1 \\ COMPUTO GENERAL DE RESTOS DE TALLA Y UTILES}

\begin{tabular}{|c|c|c|c|c|c|c|}
\hline & & & Resto & lla & & \\
\hline & Núcleos & Lascas & Otros & Total & Utiles & Total \\
\hline $\begin{array}{l}\text { Area de las Peñas del Cuervo } \\
\text { Asentamientos }\end{array}$ & & & & & & \\
\hline Cortijo del Cuervo Grande IA. & $\begin{array}{c}42 \\
13,7\end{array}$ & $\begin{array}{c}118 \\
38,69\end{array}$ & $\begin{array}{c}100 \\
32,79\end{array}$ & $\begin{array}{c}260 \\
82,25\end{array}$ & $\begin{array}{c}45 \\
14,75\end{array}$ & $\begin{array}{l}305 \\
100\end{array}$ \\
\hline Cortijo del Cuervo Grande 1B. & $\begin{array}{l}- \\
-\end{array}$ & $\begin{array}{c}2 \\
40,00\end{array}$ & $\begin{array}{l}- \\
-\end{array}$ & $\begin{array}{c}2 \\
40,00\end{array}$ & $\begin{array}{c}3 \\
60,00\end{array}$ & $\begin{array}{r}5 \\
100\end{array}$ \\
\hline Cortijo del Cuervo Grande 2. & $\begin{array}{c}34 \\
22,82\end{array}$ & $\begin{array}{c}64 \\
42,95\end{array}$ & $\begin{array}{c}37 \\
24,83\end{array}$ & $\begin{array}{c}135 \\
90,60\end{array}$ & $\begin{array}{c}14 \\
9,40\end{array}$ & $\begin{array}{l}149 \\
100\end{array}$ \\
\hline Cortijo del Cuervo Grande 3. & $\begin{array}{c}5 \\
20,83\end{array}$ & $\begin{array}{c}6 \\
25,00\end{array}$ & $\begin{array}{c}9 \\
37,50\end{array}$ & $\begin{array}{c}20 \\
83,33\end{array}$ & $\begin{array}{c}4 \\
16,67\end{array}$ & $\begin{array}{r}24 \\
100\end{array}$ \\
\hline Cortijo del Cuervo Grande 5. & $\begin{array}{c}23 \\
22,33\end{array}$ & $\begin{array}{c}36 \\
34,95\end{array}$ & $\begin{array}{c}30 \\
29,13\end{array}$ & $\begin{array}{c}89 \\
86,41\end{array}$ & $\begin{array}{c}14 \\
13,59\end{array}$ & $\begin{array}{l}103 \\
100\end{array}$ \\
\hline Peñas del Cuervo 3. & $\begin{array}{c}10 \\
16,13\end{array}$ & $\begin{array}{c}29 \\
46,77\end{array}$ & $\begin{array}{c}21 \\
33,87\end{array}$ & $\begin{array}{c}60 \\
96,77\end{array}$ & $\begin{array}{c}2 \\
3,23\end{array}$ & $\begin{array}{r}62 \\
100\end{array}$ \\
\hline Peñas del Cuervo 4. & $\begin{array}{c}4 \\
22,22\end{array}$ & $\begin{array}{c}10 \\
55,55\end{array}$ & $\begin{array}{l}- \\
-\end{array}$ & $\begin{array}{c}14 \\
77,77\end{array}$ & $\begin{array}{c}4 \\
22,22\end{array}$ & $\begin{array}{r}18 \\
100\end{array}$ \\
\hline Talleres & & & & & & \\
\hline Viña Santa Lucía 2. & $\begin{array}{c}58 \\
10,41\end{array}$ & $\begin{array}{c}310 \\
55,65\end{array}$ & $\begin{array}{c}151 \\
27,11\end{array}$ & $\begin{array}{c}519 \\
93,17\end{array}$ & $\begin{array}{c}38 \\
6,83\end{array}$ & $\begin{array}{l}557 \\
100\end{array}$ \\
\hline Peñas del Cuervo 1. & $\begin{array}{c}14 \\
24,14\end{array}$ & $\begin{array}{c}21 \\
36,21\end{array}$ & $\begin{array}{c}19 \\
32,76\end{array}$ & $\begin{array}{c}54 \\
93,11\end{array}$ & $\begin{array}{c}4 \\
6,89\end{array}$ & $\begin{array}{r}58 \\
100\end{array}$ \\
\hline Peñas del Cuervo 2. & $\begin{array}{c}8 \\
4,32\end{array}$ & $\begin{array}{c}79 \\
42,70\end{array}$ & $\begin{array}{c}73 \\
39,46\end{array}$ & $\begin{array}{c}160 \\
86,48\end{array}$ & $\begin{array}{c}25 \\
13,52\end{array}$ & $\begin{array}{l}185 \\
100\end{array}$ \\
\hline Talleres con asentamiento & & & & & & \\
\hline Las Arenas & $\begin{array}{c}101 \\
12,68\end{array}$ & $\begin{array}{c}308 \\
38,60\end{array}$ & $\begin{array}{c}312 \\
39,10\end{array}$ & $\begin{array}{c}721 \\
90,36\end{array}$ & $\begin{array}{c}77 \\
9,64\end{array}$ & $\begin{array}{l}798 \\
100\end{array}$ \\
\hline $\begin{array}{l}\text { Marisma del Cuervo } \\
\text { Asentamientos }\end{array}$ & & & & & & \\
\hline Haza de la Torre 1. & $\begin{array}{c}43 \\
22,28\end{array}$ & $\begin{array}{c}57 \\
29,53\end{array}$ & $\begin{array}{c}66 \\
34,20\end{array}$ & $\begin{array}{c}166 \\
86,01\end{array}$ & $\begin{array}{c}27 \\
13,99\end{array}$ & $\begin{array}{l}193 \\
100\end{array}$ \\
\hline Haza de la Torre 8. & $\begin{array}{c}14 \\
13,21\end{array}$ & $\begin{array}{c}43 \\
40,57\end{array}$ & $\begin{array}{c}29 \\
27,36\end{array}$ & $\begin{array}{c}86 \\
81,14\end{array}$ & $\begin{array}{c}20 \\
18,86\end{array}$ & $\begin{array}{l}106 \\
100\end{array}$ \\
\hline Haza de la Torre 7. & $\begin{array}{c}18 \\
23,68\end{array}$ & $\begin{array}{c}26 \\
34,21\end{array}$ & $\begin{array}{c}24 \\
31,58\end{array}$ & $\begin{array}{c}68 \\
89,47\end{array}$ & $\begin{array}{c}8 \\
10,53\end{array}$ & $\begin{array}{r}76 \\
100\end{array}$ \\
\hline Estación del Cuervo 1A. & $\begin{array}{c}11 \\
50,00\end{array}$ & $\begin{array}{c}5 \\
22,72\end{array}$ & $\begin{array}{c}6 \\
27,28\end{array}$ & $\begin{array}{c}22 \\
100,00\end{array}$ & - & $\begin{array}{r}22 \\
100\end{array}$ \\
\hline Haza de la Torre 5. & $\begin{array}{c}2 \\
15,38\end{array}$ & $\begin{array}{c}5 \\
38,46\end{array}$ & $\begin{array}{c}4 \\
30,77\end{array}$ & $\begin{array}{c}11 \\
84,61\end{array}$ & $\begin{array}{c}2 \\
15,38\end{array}$ & $\begin{array}{r}13 \\
100\end{array}$ \\
\hline
\end{tabular}




\section{CUADRO 2 \\ TIPOS DE NUCLEOS}

\begin{tabular}{llllllllll}
$I T$ & $L E$ & $G L$ & $P R$ & $I P G$ & $2 P G$ & $S L$ & $H O$ & $D I$ & Total \\
\hline
\end{tabular}

Area de las Peñas del Cuervo

Asentamientos

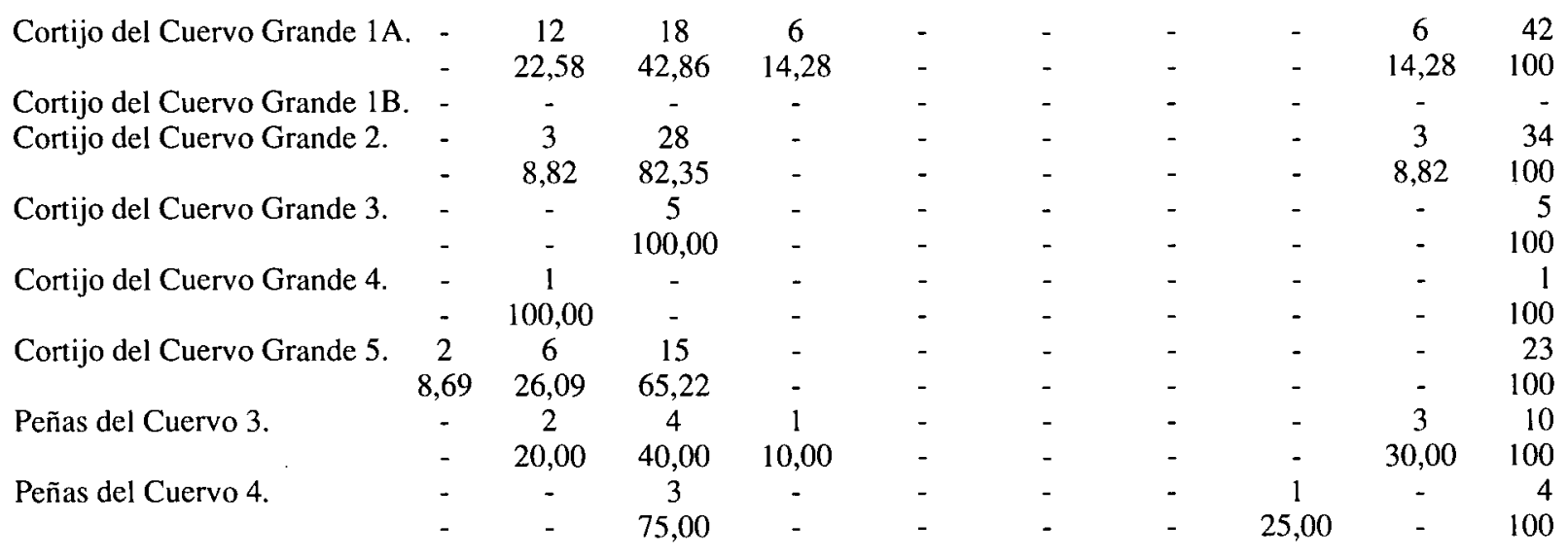

Talleres

Viña Santa Lucía 2.

Peñas del Cuervo 1.

Peñas del Cuervo 2.

$\begin{array}{ccccccccr}12 & 28 & 5 & 2 & - & 3 & 2 & 6 & 58 \\ 20,68 & 48,27 & 8,62 & 3,46 & - & 5,17 & 3,46 & 10,34 & 100 \\ 7 & 5 & - & - & - & - & - & 2 & 14 \\ 50,00 & 35,72 & - & - & - & - & - & 14,28 & 100 \\ 1 & 4 & - & - & - & 1 & 2 & - & 8 \\ 12,50 & 50,00 & - & - & - & 12,50 & 25,00 & - & 100\end{array}$

Talleres con asentamiento

Las Arenas

$\begin{array}{cccccccccc}- & 13 & 50 & 14 & 7 & 1 & 4 & 3 & 9 & 101 \\ - & 12,87 & 49,50 & 13,86 & 6,93 & 0 & 3,96 & 2,97 & 8,92 & 100\end{array}$

Marisma del Cuervo

Asentamientos

Haza de la Torre 1.

Haza de la Torre 8.

Haza de la Torre 7.

Estación del Cuervo 1A.

$\begin{array}{cccc}1 & 11 & 20 & 4 \\ 2,32 & 25,58 & 46,51 & 9,30 \\ - & 6 & 7 & 1 \\ - & 42,86 & 50,00 & 7,14 \\ - & 4 & 13 & - \\ - & 22,22 & 72,23 & - \\ - & 1 & 8 & - \\ - & 9,09 & 72,73 & - \\ - & - & 2 & - \\ - & - & 100,00 & -\end{array}$

2
4,66
-
-
-
-
-
-
-
-

\begin{tabular}{rrccr}
- & - & - & 5 & 43 \\
- & - & - & 11,63 & 100 \\
- & - & - & - & 14 \\
- & - & - & - & 100 \\
- & - & 1 & - & 18 \\
- & - & 5,55 & - & 100 \\
- & - & - & 2 & 11 \\
- & - & - & 18,18 & 100 \\
- & - & - & - & 2 \\
- & - & - & 100 & \\
\hline
\end{tabular}

TIPOS DE NUCLEOS: IT = Del inicio de la talla; LE = Levallois; $\mathrm{GL}=$ Globulosos; $\mathrm{PR}=$ Prismáticos; $1 \mathrm{PG}=\mathrm{Con}$ un plano de golpeo; $2 \mathrm{PG}=$ Con dos planos de golpeo; $\mathrm{SL}=$ Sobre lascas; $\mathrm{HO}=$ Para hojas; $\mathrm{DI}=$ Diversos. 
CUADRO 3

TIPOS DE LASCAS

\begin{tabular}{|c|c|c|c|c|c|c|c|c|}
\hline & $D E$ & $S D$ & IN & $L E$ & $C R$ & $\mathrm{HO}$ & $L D N H$ & Total \\
\hline \multicolumn{9}{|l|}{$\begin{array}{l}\text { Area de las Peñas del Cuervo } \\
\text { Asentamientos }\end{array}$} \\
\hline Cortijo del Cuervo Grande 1A. & $\begin{array}{c}4 \\
3.39\end{array}$ & $\begin{array}{c}14 \\
11.86\end{array}$ & $\begin{array}{c}67 \\
56.78\end{array}$ & $\begin{array}{c}32 \\
27,12\end{array}$ & $\begin{array}{c}1 \\
0,85\end{array}$ & - & - & $\begin{array}{l}118 \\
100\end{array}$ \\
\hline Cortijo del Cuervo Grande 1B. & - & $\begin{array}{c}1 \\
50,00\end{array}$ & - & $\begin{array}{c}1 \\
50,00\end{array}$ & - & - & - & $\begin{array}{r}2 \\
100\end{array}$ \\
\hline Cortijo del Cuervo Grande 2. & $\begin{array}{c}6 \\
9,37\end{array}$ & $\begin{array}{c}2 \\
3,13\end{array}$ & $\begin{array}{c}45 \\
70,31\end{array}$ & $\begin{array}{c}9 \\
14.06\end{array}$ & - & $\begin{array}{c}2 \\
3,13\end{array}$ & - & $\begin{array}{r}64 \\
100\end{array}$ \\
\hline Cortijo del Cuervo Grande 3. & - & $\begin{array}{c}1 \\
16,67\end{array}$ & $\begin{array}{c}5 \\
83,33\end{array}$ & $\begin{array}{l}- \\
-\end{array}$ & $\begin{array}{l}- \\
-\end{array}$ & $\begin{array}{l}- \\
-\end{array}$ & $\begin{array}{l}- \\
-\end{array}$ & $\begin{array}{r}6 \\
100\end{array}$ \\
\hline Cortijo del Cuervo Grande 4. & - & - & $\begin{array}{c}1 \\
100,00\end{array}$ & - & - & $\begin{array}{l}- \\
-\end{array}$ & $\begin{array}{l}- \\
-\end{array}$ & $\begin{array}{r}1 \\
100\end{array}$ \\
\hline Cortijo del Cuervo Grande 5. & - & $\begin{array}{c}1 \\
2,78\end{array}$ & $\begin{array}{c}28 \\
77,77\end{array}$ & $\begin{array}{c}6 \\
16,67\end{array}$ & - & $\begin{array}{c}1 \\
2,78\end{array}$ & - & $\begin{array}{r}36 \\
100\end{array}$ \\
\hline Peñas del Cuervo 3. & $\begin{array}{c}1 \\
3,45\end{array}$ & $\begin{array}{c}5 \\
17,24\end{array}$ & $\begin{array}{c}18 \\
62,09\end{array}$ & $\begin{array}{c}3 \\
10,34\end{array}$ & - & $\begin{array}{c}2 \\
6,88\end{array}$ & - & $\begin{array}{r}29 \\
100\end{array}$ \\
\hline Peñas del Cuervo 4. & $\begin{array}{l}- \\
-\end{array}$ & $\begin{array}{c}1 \\
10,00\end{array}$ & $\begin{array}{c}8 \\
80,00\end{array}$ & $\begin{array}{c}1 \\
10,00\end{array}$ & - & - & - & $\begin{array}{r}10 \\
100\end{array}$ \\
\hline \multicolumn{9}{|l|}{ Talleres } \\
\hline Viña Santa Lucía 2. & $\begin{array}{c}6 \\
1,93\end{array}$ & $\begin{array}{c}33 \\
10,65\end{array}$ & $\begin{array}{c}188 \\
60,65\end{array}$ & $\begin{array}{c}32 \\
10,32\end{array}$ & $\begin{array}{c}3 \\
0,97\end{array}$ & $\begin{array}{c}47 \\
15,16\end{array}$ & $\begin{array}{c}1 \\
0,32\end{array}$ & $\begin{array}{l}310 \\
100\end{array}$ \\
\hline Peñas del Cuervo 1. & - & - & $\begin{array}{c}18 \\
85,72\end{array}$ & $\begin{array}{c}1 \\
4,76\end{array}$ & $\begin{array}{c}2 \\
9,52\end{array}$ & $\begin{array}{l}- \\
-\end{array}$ & $\begin{array}{l}- \\
-\end{array}$ & $\begin{array}{r}21 \\
100\end{array}$ \\
\hline Peñas del Cuervo 2. & $\begin{array}{c}2 \\
2,54\end{array}$ & $\begin{array}{c}11 \\
13,92\end{array}$ & $\begin{array}{c}45 \\
56,96\end{array}$ & $\begin{array}{c}9 \\
11,39\end{array}$ & - & $\begin{array}{c}12 \\
15,19\end{array}$ & - & $\begin{array}{r}79 \\
100\end{array}$ \\
\hline \multicolumn{9}{|l|}{ Talleres con asentamiento } \\
\hline Las Arenas & $\begin{array}{c}14 \\
4,54\end{array}$ & $\begin{array}{c}56 \\
18,18\end{array}$ & $\begin{array}{c}202 \\
65,58\end{array}$ & $\begin{array}{c}25 \\
8,12\end{array}$ & $\begin{array}{c}2 \\
0,65\end{array}$ & $\begin{array}{c}7 \\
2,28\end{array}$ & $\begin{array}{c}2 \\
2,65\end{array}$ & $\begin{array}{l}308 \\
100\end{array}$ \\
\hline \multicolumn{9}{|l|}{$\begin{array}{l}\text { Marisma del Cuervo } \\
\text { Asentamientos }\end{array}$} \\
\hline Haza de la Torre 1. & $\begin{array}{c}1 \\
1,75\end{array}$ & $\begin{array}{c}5 \\
8,77\end{array}$ & $\begin{array}{c}38 \\
66,68\end{array}$ & $\begin{array}{c}9 \\
15,79\end{array}$ & $\begin{array}{c}1 \\
1,75\end{array}$ & $\begin{array}{c}3 \\
5,26\end{array}$ & - & $\begin{array}{r}57 \\
100\end{array}$ \\
\hline Haza de la Torre 8. & $\begin{array}{l}- \\
-\end{array}$ & $\begin{array}{c}10 \\
23,26\end{array}$ & $\begin{array}{c}23 \\
53,49\end{array}$ & $\begin{array}{c}8 \\
18,60\end{array}$ & $\begin{array}{l}- \\
-\end{array}$ & $\begin{array}{c}2 \\
4,65\end{array}$ & - & $\begin{array}{r}43 \\
100\end{array}$ \\
\hline Haza de la Torre 7. & $\begin{array}{l}- \\
-\end{array}$ & $\begin{array}{l}- \\
-\end{array}$ & $\begin{array}{c}25 \\
96,15\end{array}$ & $\begin{array}{c}1 \\
3,85\end{array}$ & - & $\begin{array}{l}- \\
-\end{array}$ & - & $\begin{array}{r}26 \\
100\end{array}$ \\
\hline Estación del Cuervo $1 \mathrm{~A}$. & - & - & $\begin{array}{c}4 \\
80,00\end{array}$ & $\begin{array}{c}1 \\
20,00\end{array}$ & - & - & - & $\begin{array}{r}5 \\
100\end{array}$ \\
\hline Haza de la Torre 5. & - & - & $\begin{array}{c}5 \\
100,00\end{array}$ & $\begin{array}{l}- \\
-\end{array}$ & - & - & - & $\begin{array}{r}5 \\
100\end{array}$ \\
\hline
\end{tabular}

TIPOS DE LASCAS: $\mathrm{DE}=$ De descortezado; $\mathrm{SD}=$ De semidescortezado; $\mathrm{IN}=$ Internas; $\mathrm{LE}=$ Levalolis; $\mathrm{CR}=$ De crestas; $\mathrm{HO}=$ Para hojas; $\mathrm{LDNH}=$ Lascas del desbaste para hojas. 


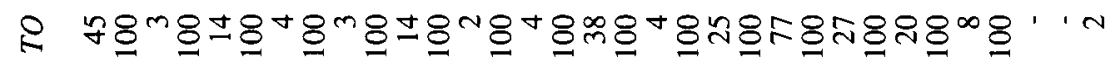

$\bar{a} \ldots \ldots \ldots, \ldots, \ldots, \ldots, \ldots, \ldots, \ldots$

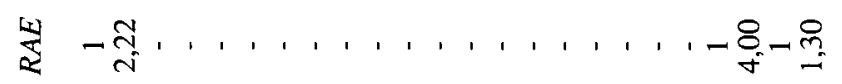

齐

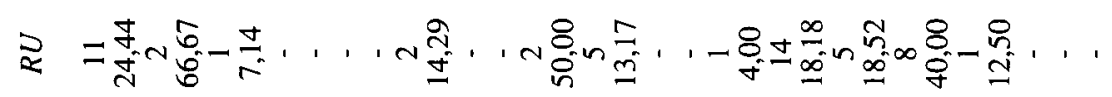

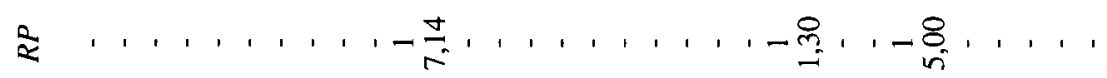

\& m

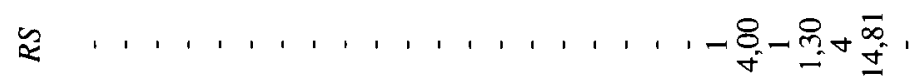

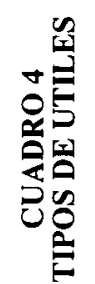

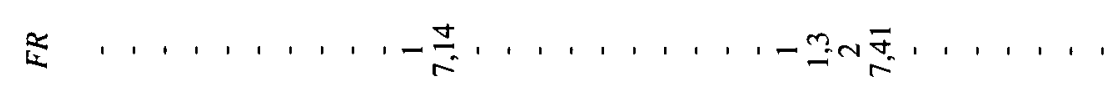

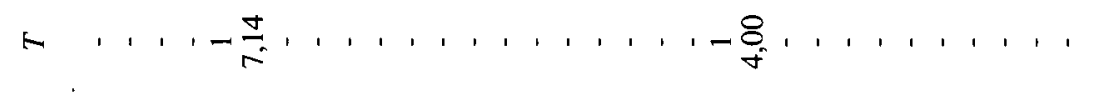

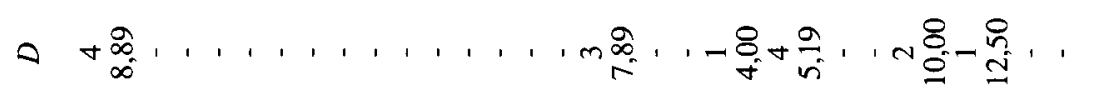

₹ 0

ฐొ

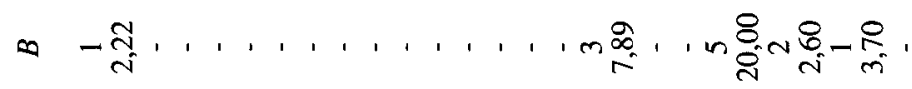

$2, \ldots, \ldots, \ldots, \ldots,-\underset{3}{8}, \ldots,-2, \ldots, \ldots$

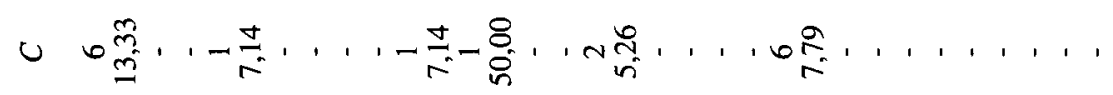

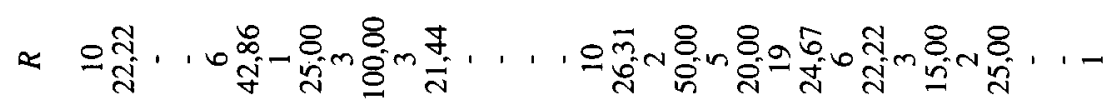

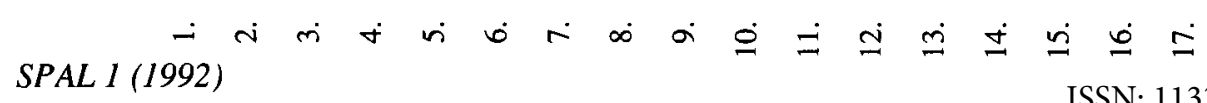




\section{CUADRO 5 \\ OTRAS INDUSTRIAS LITICAS}

\begin{tabular}{|c|c|c|c|c|c|c|c|c|c|c|}
\hline & & & pulir & dos & & & & indu & & \\
\hline & $H A$ & $M A$ & $I N$ & $F P P$ & TO & $M O$ & $M M$ & $P E$ & $A L$ & TO \\
\hline 1. & 7 & 3 & 4 & - & 14 & 4 & 7 & 1 & - & 12 \\
\hline 2. & - & - & - & - & - & - & 1 & - & - & 1 \\
\hline 3. & 3 & 3 & 9 & - & 15 & 3 & 7 & - & - & 10 \\
\hline 4. & - & - & - & - & - & 2 & 1 & - & - & 3 \\
\hline 5. & - & - & - & - & - & - & - & - & - & - \\
\hline 6. & - & - & 1 & - & 1 & - & - & - & - & - \\
\hline 7. & - & - & - & - & - & 2 & 1 & - & - & 3 \\
\hline 8. & - & - & - & - & - & - & - & - & - & - \\
\hline 9. & - & - & - & - & - & - & - & - & - & - \\
\hline 10 & - & - & - & - & - & - & - & - & - & - \\
\hline 11. & - & - & - & - & - & - & - & - & - & - \\
\hline 12. & 1 & 2 & - & 3 & 6 & 1 & - & - & 1 & 1 \\
\hline 13. & 1 & - & - & 5 & 6 & 2 & 3 & - & - & 5 \\
\hline 14. & - & - & - & - & - & - & - & - & - & - \\
\hline 15. & 1 & - & - & - & 1 & 1 & 1 & - & 2 & 4 \\
\hline 16. & - & 1 & - & - & 1 & - & - & - & - & - \\
\hline 17. & 1 & - & 1 & - & 2 & 1 & - & 1 & - & 2 \\
\hline
\end{tabular}

1 = Cortijo del Cuervo Grande 1 A.

$2=$ Cortijo del Cuervo Grande 1B.

$3=$ Cortijo del Cuervo Grande 2.

4 = Cortijo del Cuervo Grande 3.

$5=$ Cortijo del Cuervo Grande 4.

$6=$ Cortijo del Cuervo Grande 5.

7 = Peñas del Cuervo 3.

$8=$ Peñas del Cuervo 4 .
9 = Viña Santa Lucía 2.

$10=$ Peñas del Cuervo 1.

11 = Peñas del Cuervo 2.

12 = Las Arenas

13 = Haza de la Torre 1.

$14=$ Haza de la Torre 8.

$15=$ Haza de la Torre 7.

16 = Estación del Cuervo $1 \mathrm{~A}$.

17 = Haza de la Torre 5.

INDUSTRIA LITICA PULIMENTADA: HA = Hachas; MA = Martillos; IN = Indeterminados; FPP = Fragmentos pulimentados partidos.

OTRAS INDUSTRIAS LITICAS: $\mathrm{MO}=$ Molinos; $\mathrm{MM}=$ Manos de molino; $\mathrm{PE}=$ Percutores; $\mathrm{AL}=\mathrm{Alisadores} ; \mathrm{TO}=\mathrm{Total}$. 